\title{
Seismic and Structural Health Monitoring Systems For Large Dams: Theoretical, Computational and Practical Innovations
}

\section{Sérgio Oliveira ( $\square$ sbmoliveira@gmail.com )}

Laboratório Nacional de Engenharia Civil: Laboratorio Nacional de Engenharia Civil https://orcid.org/0000-0003-3309-5897

\section{André Alegre}

Universidade de Lisboa Instituto Superior Técnico: Universidade de Lisboa Instituto Superior Tecnico

\section{Ezequiel Carvalho}

HCB: Hidroeléctrica de Cahora Bassa

\section{Paulo Mendes}

Instituto Politécnico de Lisboa Instituto Superior de Engenharia de Lisboa: Instituto Politecnico de Lisboa Instituto Superior de Engenharia de Lisboa

\section{Jorge Proença}

Universidade de Lisboa Instituto Superior Técnico: Universidade de Lisboa Instituto Superior Tecnico

\section{Research Article}

Keywords: Dynamic behavior of large concrete dams, Finite element numerical modelling, Seismic and Structural Health Monitoring, Safety control, Dam reservoir-foundation systems, Evolution of natural frequencies, Vibration modes, Seismic response

Posted Date: June 17th, 2021

DOl: https://doi.org/10.21203/rs.3.rs-597616/v1

License: (c) (i) This work is licensed under a Creative Commons Attribution 4.0 International License. Read Full License

Version of Record: A version of this preprint was published at Bulletin of Earthquake Engineering on April 2nd, 2022. See the published version at https://doi.org/10.1007/s10518-022-01392-1. 


\section{Abstract}

Over the past decade, monitoring systems for Seismic and Structural Health Monitoring (SSHM) have been assuming a greater role in the safety control of large concrete dams. In this article, the dynamic behavior of two large arch dams equipped with SSHM systems is analyzed, in order to present some of the main theoretical, computational and practical innovations developed recently for the improvement of large dams' continuous dynamic monitoring using SSHM systems. The case studies are two large arch dams that have been under continuous dynamic monitoring over the last ten years: Cabril dam (132 m high), the highest dam in Portugal, and Cahora Bassa dam (170 m high), located in Mozambique, one of the highest dams in Africa.

The Seismic and Structural Health Monitoring (SSHM) systems installed in both dams have similar schemes and were designed to continuously record acceleration time series in several locations at the upper part of the dam body and near the dam-foundation interface, using uniaxial and triaxial accelerometers. Specific software was developed for monitoring data analysis, including automatic modal identification, to obtain natural frequencies and mode shapes, for automatic detection of vibrations induced by seismic events, to be distinguished by those caused by other operational sources, and for comparison between results retrieved from measured vibrations and numerical results obtained from computational 3DFE models. The numerical analyses are carried out using a 3DFE program for linear and non-linear dynamic analysis of concrete dams, based on a solid-fluid coupled formulation to simulate the dam-reservoir-foundation system, considering the dam-water dynamic interaction and the propagation of pressure waves throughout the reservoir.

The most significant experimental results from continuous dynamic monitoring are presented for Cabril dam and Cahora Bassa dam and compared with numerical results, with emphasis on the evolution of natural frequencies over time, on vibration mode shapes for various water levels, and, finally, on the measured accelerations during seismic events. Furthermore, the main results of non-linear seismic response simulations, considering joint movements and concrete damage, are also presented for both dams in order to assess their seismic performance, using an intensifying seismic accelerogram prepared for Endurance Time Analysis.

\section{Introduction}

Large concrete dams play a major role in the management of water resources by making a decisive contribution to water supply, flood control, irrigation, and electrical energy production. In general, these are structures of high potential risk, since incidents or accidents involving this type of dams can result in significant losses for populations and the environment(Wieland, 2016). According to the International Commission on Large Dams (ICOLD) it is therefore fundamental to evaluate their performance in normal operating conditions and under seismic events(ICOLD, 2018, 2019), particularly in the case of dams subject to concrete deterioration phenomena and/or those located in areas of medium-high seismicity 
(Fig.1). Furthermore, aiming to ensure the best operating and safety conditions for large concrete dams, their structural safety must be evaluated for current and failure scenarios, understatic and dynamic loads.

In this scope, it should be emphasized the importance and the need to develop: (i) systems for Seismic and Structural Health Monitoring (SSHM) of large dams, which should include high quality devices for data measurement, acquisition, transmission, and storage, as well as appropriate software for automatic management and analysis of collected data; (ii) advanced 3D finite element (3DFE) models of damreservoir-foundation systems - which should be able to predictthe dam response under various scenarios that can occur over the lifetime of dams, involving the variation of the static and dynamic loads, structural changes due to deterioration processes and non-linear behavior; (iii) computational programs to carry out linear and non-linear dynamic simulations; and (iv) appropriate methodologies for analyzing the main results, enabling the comparison of the measured response with the predicted behavior and the interpretation of results from non-linear seismic simulations.

The combined used of experimental data and numerical results (Alegre, Carvalho, et al., 2019; Oliveira \& Alegre, 2020) can be of great value not only to increase knowledge on the dynamic behavior of large concrete dams, but also for improving their safety control, namely (i) to detect eventual processes of evolutive deterioration, using methodologies based on the analysis of ambient/operational vibrations; (ii) to characterize the seismic actions and to control the seismic response during low, medium, or high intensity seismicaccelerations; and (iii) to calibrate and validate existing numerical models and help in the development of new ones. In addition, results from non-linear seismic response analysis can provide useful information on the seismic performance of large concrete dams and support studies for seismic safety assessment (Alegre, Oliveira, et al., 2020; Alegre \& Oliveira, 2020).

This work is focused on studying the dynamic behavior of two large arch dams, by providing valuable experimental and numerical results, aiming to show some of the main theoretical, computational, and practical innovations developed in recent years for the improvement of continuous dynamic monitoring systems for large concrete dams. Therefore, after a general overview on the importance of SSHM systems in the safety control of large concrete dams and on the numerical modelling of the dynamic behavior of dam-reservoir-foundation systems, the developed software is presented. First, the software designed to integrate and complement the SSHM systems installed in large concrete dams is described, which includes computational tools: (i) for automatic analysis and management of continuous dynamic monitoring data, aiming to assess data quality, to automatically detect vibrations induced by seismic events, and to perform the maintenance of the database; and (ii) for automatic modal identification, based on the frequency domain decomposition method and using a new methodology to automate and optimize the selection of spectral peaks. Then, the 3D finite element model developed to simulate the dynamic behavior of dam-reservoir-foundation systems, based on a coupled formulation in displacements and pressures, is presented. The implemented computational model has three modules, namely for: (i) complex modal analysis, using a state-space formulation that allows to consider generalized damping; (ii) linear seismic response analysis, based on a time-stepping algorithm for numerical time integration based on the Newmark method; and (iii) non-linear seismic analysis, 
considering the non-linear behavior of concrete up to failure,and the opening/closing and sliding movements of joints and cracks in the dam body.

The case studies are Cabril dam, $132 \mathrm{~m}$ high, in Portugal, and Cahora Bassa dam, $170 \mathrm{~m}$ high, in Mozambique,two double curvature arch dams that have been under continuous dynamic monitoring since 2008 and 2010, respectively. The most important results from studies carried out in recent years are provided, with focus on: (i) the analysis of the evolution of the identified natural frequencies over time and the comparison with the corresponding numerical values, aiming toevaluate the influence of the reservoir water level variations and to perform vibration-based detection of evolutive damage; (ii) the study of the measured response during seismic events, based on the comparison between recorded and computed accelerations in various positions of the dam body, in order to investigate the base-to-top amplification factors and the damping ratios required in the numerical models; and (iii) the assessment of the non-linear seismic response under a strong seismic excitation, using an intensifying seismic accelerogram prepared for Endurance Time Analysis (ETA), with the goal of evaluating the seismic safety based on tensile and compressive damage distributions in the dam body.

\section{The Role Of Sshm Systems In The Safety Control Of Large Concrete Dams}

The Seismic and Structural Health Monitoring concept has emerged and asserted itself on a global level in the past years, not only due to the needs of owners, managers and users, but also to the inherent advantages of SSHM and the useful data that can be provided to engineers and researchers, for dynamic behavior monitoring and structural safety control(Limongelli, 2020). Thus, this type of monitoring systems have been installed and used in large structures all over the world, such as tall buildings, longspan bridges, large dams and other important structures (Li et al., 2016; Limongelli \& Çelebi, 2019).

The importance of the observation and analysis of the behavior of large concrete dams has been widely recognized for decades(Pedro, 1999; Ramos, 1994), especially when experimental data is used in combination with numerical modelling results. Regarding dynamic behavior monitoring for structural safety control of large concrete dams, the popularity of continuous dynamic monitoring systems has grown significantly over the last decade(Oliveira \& Alegre, 2019),, due to the recognition of the advantages of continuous vibrations monitoring for increasing knowledge on the dynamic behavior of dam-reservoir-foundation systems(Alegre, Carvalho, et al., 2019; Bukenya et al., 2014; Bukenya \& Moyo, 2017; Oliveira et al., 2012), as well as for detecting and controlling deterioration processes(Oliveira \& Alegre, 2020), both progressive deterioration due to phenomena like concrete swelling or deterioration induced by exceptional events such as floods or major earthquakes. Therefore, and considering the need to evaluate the performance of dams in normal operating conditions over time and during seismic events(ICOLD, 2018, 2019)the installation of monitoring systems for continuously measuring vibrations has been proposed for new large dams, to evaluate their performance since the first filling of the reservoir, and for some older dams, built decades ago and with possible deterioration problems, to (re-)assess their structural health. Furthermore, due to the lack of available data worldwide,this type of systems can also 
be extremely useful to obtain additional data for characterizing the seismic actions and for studying the seismic response of large concrete dams under low/medium/high intensity earthquakes.

In Portugal, the continuous dynamic monitoring of large concrete dams started in 2008, in the scope of a pioneer project (Oliveira, 2002) for the development and installation of a SSHM system in Cabril to continuously measure vibrations in normal operating conditions and during seismic events(Mendes, 2010), which was funded by the Portuguese Foundation for Science and Technology (FCT) and supported byEnergias de Portugal (EDP). In light of the success achieved with Cabril dam and of the valuable results obtained in various studies (Alegre, Carvalho, et al., 2019; Alegre, Robbe, et al., 2020; Oliveira et al., 2012, 2014; Oliveira \& Alegre, 2020, 2018), the decision was made to invest in the installation of similar SSHM system at BaixoSabor dam(Gomes et al., 2018; Pereira et al., 2017)and Foz Tua dam (Pereira et al., 2021; Silva Matos et al., 2019), as well as of trigger-event type systems for measuring seismic vibrations in Alqueva, Alto Ceira II and Ribeiradio dams.

In Africa, continuous dynamic monitoring of large concrete dams began in 2010, when Hidroelétrica de Cahora Bassa (HCB) decided to install a SSHM system in Cahora Bassa dam(Carvalho et al., 2014; Carvalho \& Matsinhe, 2014; Carvalho \& Tembe, 2012)to enable the continuous evaluation of its behavior in normal operating conditions and to measure the responseduring seismic events. Later, in 2013, a continuous dynamic monitoring system was also installedfor structural health monitoring of RoodeElsberg dam, located in Worcester, Western Cape, South Africa, after ambient vibration tests had been carried out for several years(Bukenya \& Moyo, 2017).

Examples of large concrete dams currently under continuous dynamic monitoringworldwide include Enguri arch dam, $271.5 \mathrm{~m}$ high, in Georgia, Beli Iskar gravity dam, $51 \mathrm{~m}$ high, in Bulgaria, Xiangjiaba gravity dam, $161 \mathrm{~m}$ high, in China, as well as other 23 dams in South Korea (www.geosig.com/Damspg38).

For safety control of large concrete dams, SSHM systems should ideally be designed to measure in as many locations of the dam body as possible, in several positions along the dam base, and, eventually, in the rock mass foundation (free field), aiming at the continuous evaluation of the dynamic performance of dams in normal operating conditions and when earthquakes hit the dam site. With that goal, the measurement devices should be configured with a high dynamic range, enabling the accurate measurement of low amplitude vibrations, induced by ambient or operational sources or by low intensity earthquakes, and of high amplitude vibrations, caused by strong earthquakes or other exceptional occurrences(Mendes, 2010). Moreover, these monitoring systems should include cutting-edge and highquality equipment for automatic data measurement, acquisition, and transmission, including digitizers, recorders, transducers, accelerometers, data concentrators, etc., which are usually provided by specialized companies. Nevertheless, it is vital to complement the hardware component by developing suitable software, which must naturally be adapted and optimized to each dam and the respective SSHM system. This software should include computational tools to automatically process, manage and analyze the continuously measured data, as well as to enable the comparison between experimental and numerical 
results, in order to obtain useful data for dynamic behavior analysis and for supporting seismic response monitoring and structural health monitoring (Oliveira \& Alegre, 2020).

Based on the experience gathered over the past decade in this field, particularly from studies on the dynamic behavior of Cabril dam and Cahora Bassa dam, the combined use of experimental information

extracted from continuous dynamic monitoring data and of numerical results obtained with advanced FE models (Fig. 2) has proven that it can be extremely useful for dynamic behavior analysis and safety control of dams, namely: (i) to study the evolution of modal parameters (natural frequencies, mode shapes and damping ratios) over time, enabling to evaluate the influence of water level variations or thermal variations(Alegre, Carvalho, et al., 2019; Bukenya \& Moyo, 2017; Ueshima et al., 2017) in the dynamic response of dam-reservoir-foundation systems, and to investigate the effects due to ageing of dams, evolutive deterioration phenomena or damage due to strong earthquakes, by comparing the observed behavior at a certain point in time with a specific reference state(Alegre, Oliveira, et al., 2020; Oliveira \& Alegre, 2020); (ii) to automatically identify vibrations induced by low, medium, or high intensity seismic events, and study the seismic response based on recorded accelerations, allowing to analyze the base-to-top acceleration amplification factors and to investigate the damping ratios(Chopra \& Wang, 2010; Proulx \& Darbre, 2008; Robbe et al., 2017); and (iii)to calibrate and validate existing numerical models, and support the development of new ones, to be used as reference models in future behavior prediction studies(Oliveira et al., 2014; Sevim et al., 2011).

\section{Numerical Models: Dynamic Behavior Of Dam-reservoir-foundation Systems}

Large concrete dams are civil engineering structures of considerable dimensions, with unique and complex geometry. Furthermore, their behavior under static and dynamic loads is considerably influenced by the interaction with the reservoir and the foundation, as they are part of a complex dam-reservoirfoundation system(Câmara, 1989; Pedro \& Câmara, 1986). Moreover, the properties of the dam-reservoirfoundation system and thus its global behavior can change significantly over time, namely due to reservoir water level and/or thermal variationsand due to structural changes in the dam body, caused by processes of concrete deterioration over timeand/orirreversible movements of contraction joints or other discontinuities. Therefore, it is essential to develop advanced models for the analysis of dam-reservoirfoundation systems, considering the various scenarios that can occur over the lifetime of dams,involving the variation of the dynamic properties and of the static and dynamic loads, structural changes due to deterioration processes, and non-linear behavior.

The numerical modelling of the dynamic behavior of large concrete dams, considering the interaction between all parts of the dam-reservoir-foundation system and linear or non-linear behavior,is a field where extensive work has been conducted, leading to the development of various well-established models and formulations, mostly based on the Finite Element Method(Zienkiewicz, Taylor, \& Zhu, 2013). 
The simulation of the dam-reservoir dynamic interaction can be carried out using the classic added water mass models, using displacement-based formulations for the solid domain and Westergaard's solution to compute water masses equivalent to the hydrodynamic pressures(Westergaard, 1933). As an alternative, there are the coupled models, which require the reservoir discretization and the definition of finite element formulations for both the solid (dam and foundation) and fluid (reservoir) domains, considering boundary conditions at the main interfaces of the system(Zienkiewicz \& Bettess, 1978). A possible solution consistsin assuming a displacement-based formulation for both the solid and fluid domains (Belytschko, 1980): in this case, nodal displacements are assumed as the main variablesfor the whole dam-reservoirfoundation system, and the water is assumed as an elastic solid with negligible shear modulus. However, the best approach are the coupled modelsformulated in displacements for the solid domain and in hydrodynamic pressures(Zienkiewicz, Taylor, \& Zhu, 2013) or velocity potentials(Bouaanani \& Lu, 2009) for the fluid domain, considering appropriate boundary conditions to simulate the dynamic dam-water motion coupling, the propagation of pressure waves in the reservoir and radiation damping in the water mass.

In what concerns the foundation and seismic input modelling, the simplest approach is based on the massless foundation model(Clough, 1980), considering a deformable and massless foundation block, with a rigid boundary at the base, where the seismic input is applied (without spatial variation). In this case, the massless foundation can be computed based on the substructure method(Fenves et al., 1989; Fok et al., 1986) by calculating stiffness and damping components of the foundation block that are incorporated at the dam-rock interface, while the seismic input is applied directlyat the dam base, either as uniform ground motion or spatial variating ground motion(Wang \& Chopra, 2010). Alternatively, the massed foundation approach is based on more complex energy dissipating models that take into account the dam-foundation interactionand wave propagation and radiation damping in the rock mass(Zhang et al., 2009), e.g. using viscous-spring boundaries(Lysmer \& Kuhlemeyer, 1969) or transmitting boundaries in the foundation block limits(Liao et al., 1984). For this type of model, the seismic input can be simulated by compression/shear waves vertically propagating from the base of the foundation(Zhang et al., 2009) or by applying the specified free-field motion directly at the dam-rock interface(Wang et al., 2013).

The numerical modelling of the dynamic behavior of a dam can be performed for modal analysis, to calculate natural frequencies, mode shapes, and damping values, and for seismic analysis under low, medium, or high intensity earthquakes, to evaluate the linear or non-linear seismic response.

To perform modal analysis, the eigenproblem of the dam-reservoir-foundation system must be solved to calculate the main modal parameters. For symmetric problems, using added water mass models, the free vibration solution can be computed by solving a standard eigenproblem(Clough \& Penzien, 2003; Mendes, 2010), with null or proportional damping, to get real eigenvalues, or using a state space formulation(Brincker \& Ventura, 2015; Oliveira et al., 2011), if generalized or non-proportional damping is considered, to obtain complex eigenvalues and eigenvectors(Veletsos \& Ventura, 1986). For nonsymmetric problems with coupled models, standard solutions cannot be applied. In such cases, special 
solutions can be implemented to achieve an equivalent symmetric problem, without damping, and thus solve a standard eigenproblem with real eigenvalues and eigenvectors(Sani \& Lofti, 2010; Zienkiewicz, Taylor, \& Zhu, 2013). Alternatively, it is possible to use a coupled state-space formulation to solve a complex eigenproblem for the whole dam-reservoir-foundation system with generalized damping, resulting in complex eigenvalues and eigenvectors that correspond to non-stationary vibration modes(Oliveira \& Alegre, 2020, 2018).

In order to carry out seismic analysis, the forced dynamic response of the dam-reservoir-foundation system must be calculated, using seismic accelerations as the dynamic load input. In studies using added water mass models with linear behavior, the response can be computed as a linear combination of the modes using the modal decomposition method or approximated in time-domain by applying timestepping procedures for numerical integration(Clough \& Penzien, 2003; Zienkiewicz, Taylor, \& Zhu, 2013). As for studies with coupled models (non-symmetric problems), the modal decomposition method is not viable and the use of time-stepping procedures is required, either based on a modified approach, where the coupled problem is mathematically manipulated to achieve an equivalently symmetric form(Zienkiewicz, Taylor, \& Zhu, 2013), or by implementing a coupled time-stepping procedure to solve the dynamic equation of the global dam-reservoir-foundation system(Alegre, Oliveira, et al., 2019). In what concerns scenarioswhere non-linear behavior must be assumed, e.g. under strong earthquakes, the dynamic properties of the dam will not remain constant and thus step-by-step methods for numerical integration must be applied, in combination with non-linear iterative procedures(Zienkiewicz, Taylor, \& Fox, 2013).

With regard to the seismic response analysis of concrete arch dams, the seismic simulations can be conducted considering linear-elastic behavior, using linear constitutive models for concrete and assuming the joints remain closed. This approach is valid under low intensity earthquakes, which are commonly measured on site using continuous or trigger-event dynamic monitoring systems and induce low amplitude vibrations in the dam body. Nevertheless, strong earthquake can induce significant inertia forces in the dam, resulting in movements of the vertical joints or other discontinuities(Chen, 1994; Fenves et al., 1992; Lau et al., 1998; Niwa \& Clough, 1982), which will alter the structural response, as well as in high tensions and compressions that can cause tensile and compressive damages(Cervera et al., 1995; Espandar \& Lotfi, 2003; Faria et al., 1998; Valliappan et al., 1999). Consequently, for non-linear seismic calculations the use of complex non-linear constitutive models is required, in order to simulate the opening/closing and sliding joint movements and the concrete behavior up to failure under tension and compression(Alegre, Oliveira, et al., 2020; Alegre \& Oliveira, 2020).

It is worth mentioning that there are many well-established and reliable numerical modelling programs used in current practice for dynamic analysis of concrete dams, including EACD-3D (Wang \& Chopra, 2008) (J.-T. Wang \& Chopra, 2008), ANSYS(ANSYS Inc., 2020), the open-source software Code_Aster (http://www.code-aster.org) and 3DEC (Lemos, 1998). However, the development and implementation of their own methodologies and codes by researchers entails several advantages as shown in this work, as this allows to have a great knowledge and control over all variables and algorithms, which can be 
constantly updated and optimized, and to manipulate the graphical outputs at will, namely the graphical outputs for comparison between numerical and experimental information from SSHM systems.

\section{Used Software: Monitoring Data Analysis And Finite Element Dynamic Analysis}

The main goal of this work is to present the most important experimental and numerical results from studies on the dynamic behavior of two large concrete arch dams. In order to carry out those studies, it was necessary to use software (Fig. 3), specifically developed for: (i) monitoring data analysis, including automatic modal identification (DamModalID) andautomatic detection of vibrations due to seismic events (DamSeismicVibID); and (ii) structural dynamic analysis using 3DFE models, in particular for modal analysis and linear and non-linear seismic analysis(DamDySSA). Thedeveloped programs are described next, in order to highlight the most recent innovations in the software component for SSHM systems.

The software developed for analyzing continuous monitoring data from SSHM systems installed in large concrete dams includes essentially two modules:(i)DamModalID, was developed for automatic modal identification of dams, to enable the estimation of natural frequencies and modal configurations. The implemented methodology is based on the Frequency Domain Decomposition method with Singular Value Decomposition (FDD-SVD)(Brincker \& Ventura, 2015), and it uses a special technique to automate the selection of peaks from the singular values spectra (Fig. 4) and a new procedure to enhance modal identification, considering the real reservoir level variations; and (ii) DamSeismicVibID, for automatic detection of vibrations induced by seismic events, usessimplified pattern analysis on the recorded acceleration time histories to distinguish the seismic vibrationsfrom the vibrationscaused by other sources, such as the operation of spillway gates or the operation of the turbines for electric power generation. Furthermore, both modules include graphical tools that enable the automatic generation of useful graphics, e.g., the evolution of natural frequencies over time, 2D modal configurations, and the recorded acceleration time histories. With these graphical tools,thestudies based on the comparison between experimental data and numerical results, can be improved. The goal is to provide useful data for owners and engineers responsible for the safety control and health monitoring, and thus to support informed management in face of regular maintenance needs or eventual emergency situations(Oliveira \& Alegre, 2020).

The numerical simulations are carried out in this work using DamDySSA4.0, the latest version of a 3D FE program developed for dynamic analysis of concrete dams and optimized for studying arch dams (Fig. 5). The dynamic behavior of dam-reservoir-foundation systems is simulated with a coupled model, using a FE-based formulation in displacements (dam and foundation) and pressures (reservoir). Boundary conditions are prescribed at the main interfaces in order to consider the dam-reservoir dynamic interaction, the propagation of pressure waves, the effect of radiation damping in the reservoir, and the reservoir free surface condition(Zienkiewicz, Taylor, \& Zhu, 2013). Furthermore, generalized damping is considered, with the natural viscous damping in the solid domain and energy dissipation due to radiation 
in the fluid domain. The substructure method is used to calculate the foundation block as an elastic and massless substructure, considering equivalent stiffness and damping components incorporated in the dam-rock interface, while the seismic input is uniform and applied directly at the dam base.

In thepresent version of the program DamDySSA there are three modules: (i) for complex modal analysis, using a coupled state-space approach that enables the consideration of generalized damping, and the computation of natural frequencies, non-stationary modes, and damping ratios of the whole damreservoir-foundation system; (ii) for linear seismic analysis, using a coupled time-stepping procedure for numerical integration based on the Newmark method, assuming linear elastic behavior for concrete and joints; and (iii) for non-linear seismic analysis, by combining the time-stepping procedure with a stress transfer method, to account for the redistribution of unbalanced stresses, and considering the concrete behavior up to failure, based on an isotropic damage model(Oliveira \& Faria, 2006) with softening and two independent scalar damage variables ( $\mathrm{d}^{+}$for tension and $\mathrm{d}^{-}$for compression), and the opening/closing/sliding joint's movements, using a simple constitutive model based on the MohrCoulomb failure criterion and appropriate relative displacement-stress laws. The main outputs of DamDySSA4.0 include 3D graphic representations of mode shapes, deformed shapes with joint movements, stress fields at both upstream and downstream faces, acceleration time histories, and tensile and compressive damage distributions.

The next two sections are dedicated to the application studies on the dynamic behavior of Cabril dam and Cahora Bassa dam. First, detailed descriptions of the dams and their SSHM systems are given. Then, the main results obtained from the continuous dynamic monitoring are provided, including analysis of natural frequencies and mode shapes and of recorded accelerations during seismic events, and numerical results from non-linear simulations are presented for seismic safety assessment.

\section{Cabril Dam}

\subsection{Dam characteristics and installed SSHM system}

Cabril dam, the highest dam in Portugal (Fig. 6), has been in operation since 1954. Located on the Zêzere river, it is a $132 \mathrm{~m}$ high double curvature arch dam, with a $290 \mathrm{~m}$ long crest, at the elevation $297 \mathrm{~m}$. The central section maximum thickness is of about $20 \mathrm{~m}$ at the dam base, and the minimumthickness is $4.5 \mathrm{~m}$, about $10 \mathrm{~m}$ below the crest (see central section in Fig.6). Regarding the foundation, Cabril dam was constructed on a good quality granite rock mass. The reservoir water level usually ranges from a minimum at el. $265 \mathrm{~m}$ to the maximum storage level at el. $295 \mathrm{~m}$. Concerning the appurtenant works there is a reinforced concrete intake tower upstream of the dam, which is connected to the crest of central cantilever through a concrete walkway, with a joint in the dam-tower contact.

In what concerns the dam's structural health, it is worth mentioning that horizontal cracking was observed at upper part of the downstream face, around el. $280 \mathrm{~m}$ to $290 \mathrm{~m}$, during the first filling of the reservoir. Also, a concrete swelling process was detected in the late 1990s. 
The continuous dynamic monitoring system of the Cabril dam was conceived and implemented as part of a research project(Oliveira, 2002), financed by the FCT and supported by EDP, carried out in collaboration with the Department of Concrete Dams and the Scientific Instrumentation Center of LNEC.The development of this system(Mendes, 2010) involved the design of the monitoring scheme, the assembling and installation of all equipment (optical fiber networks, data concentrators, accelerometers, etc.), and finally the development of software for automatic data processing, management, and analysis. The goal of this SSHM system was to continuously monitor the dam's dynamic behavior over time in normal operating conditions and to measure the dam response during seismic events.

Therefore, the monitoring scheme (Fig. 7) was outlined to record accelerations at the upper part of the dam structure and near the dam-rock interface, using 16 uniaxial (EpiSensor ES-U2) and 3 triaxial (EpiSensor ES-T) force balance accelerometers from Kinemetrics, Inc. (https://kinemetrics.com/). The uniaxial sensors measure accelerations in the radial direction: 9 are located in the upper gallery, at el. $294 \mathrm{~m}$, below the crest, and 7 are positioned in the second gallery, at el. $274 \mathrm{~m}$, below the cracked zone. As for the triaxial sensors, one is installed in the upper gallery, in the central section, while the other two are located inside the dam base gallery, in both banks, around el. $274 \mathrm{~m}$. Aiming to achieve a high dynamic range(Mendes, 2010), to enable the accurate measurement of low amplitude vibrations, due to ambient/operational sources or lower intensity earthquakes, and high amplitude vibrations, cause by strong earthquakes, full-scale recording ranges of $\pm 0.25 \mathrm{~g}$ and of $\pm 1 \mathrm{~g}$ were prescribed for uniaxial and triaxial sensors, respectively. In what concerns data acquisition and transmission, all 25 channels are connected to a modular system, composed by an optical fiber network and four data acquisition units that gather all recorded data, which is then sent to the central computer server installed in the office at the dam's power plant. Basically, 25 acceleration time histories are recorded, in 24 bit and at a sampling rate of $1000 \mathrm{~Hz}$, collected, and stored in the central server, every hour. The system was not active during some periods over the first decade of monitoring, due to either malfunctions or damages in sensors and/or data acquisition units. However, the several visits for maintenance and repairs, the system has been fully operational since June 2008.

In order to ensure a proper operation of the system and to provide useful information on Cabril dam's behavior, the SSHM system was complemented with the installation of specific software, namely for collecting and processing measured data, automatic data management and analysis, including the module for detection of vibrations induced by seismic events (DamSeismicVibID), and for automatic modal identification of dams (DamModalID). 5

\subsection{Numerical Model of Cabril dam}

The linear and non-linear dynamic behavior of Cabril dam is simulated using the program DamDySSA and the 3DFE model of the dam-reservoir-foundation system presented in Fig. 8. The dam concrete and the foundation rock are isotropic materials, considering Young's modulus E $=25 \mathrm{GPa}$ and Poisson's ratio $v=0.2$, assuming a factor of 1.3 applied to $E$ for dynamic calculations. The water in the reservoir is a 
compressible fluid with a pressure wave propagation velocity of $c_{w}=1440 \mathrm{~m} / \mathrm{s}$ (mean temperature of around $15^{\circ} \mathrm{C}$ ). The existing cracking band is simulated as a single horizontal crack, incorporated by introducing duplicate notes and joint elements at el. $285 \mathrm{~m}$. However, the current model does not include the intake tower.

For linear dynamic analysis, the concrete has linear behavior (no damage) and a version of the model without any joints is used. As for non-linear seismic analysis, the non-linear behavior of concrete up to failure is simulated using a strain-softening constitutive damage model, considering tensile strength $f_{t}=3 \mathrm{MPa}$ and compressive strength $f_{t}=-30 \mathrm{MPa}$; moreover, all vertical contraction joints and the surface along the dam-foundation interface are incorporated into the model, considering appropriate normal and shear stiffness values and stress-displacement laws to simulate opening/closing and sliding movements.

\subsection{Modal Analysis. Evolution of natural frequencies over time}

This section presents results on the dynamic behavior of Cabril dam in normal operating conditions, under ambient/operational vibrations, for the monitoring period between December 2008 and December 2020. The natural frequencies and modal configurations identified using DamModalID are presented and compared with numerical results obtained with DamDySSA. The aim is, on the one hand, to evaluate the influence of reservoir level variations on the dynamic behavior of the dam-reservoir-foundation system, and, on the other hand, to show how this study can be of value for vibration-based damage detection.

Fig. 9 shows the evolution of the identified natural frequencies for the first five vibration modes of Cabril dam, for the whole monitoring period (2008-2020), with a reservoir level variation from el $261.5 \mathrm{~m}, 31.5 \mathrm{~m}$ below the crest, to el. $295 \mathrm{~m}, 2 \mathrm{~m}$ below the top, representing a maximum $33.5 \mathrm{~m}$ variation. Based on these results it is possible to see that the dynamic properties of the dam-reservoir-foundation system and thus the dynamic behavior the dam are clearly affected by the water level in the reservoir, given that the frequency values follow the water level variations over time: the higher the water level, the higher the global mass of the system, the lower the frequency values. This effect is more noticeable for the modes with higher natural frequencies. As for thermal variations, the air temperature amplitude of only around \pm $8^{\circ}$ over the year, and thus its influence in the dynamic response of the dam is not considered here.

Furthermore, the modal identification results show the frequencies associated with the operation of the energy production groups, with rotation frequency of $3.57 \mathrm{~Hz}$, as well as the detection of modes that are most likely associated with the vibrations of the intake tower - for lower water levels, the tower leans against the dam, inducing a certain dam-tower dynamic interaction(Mendes \& Oliveira, 2009) while for higher water levels the joint opens and tower and dam are separated. 
The frequencies and modal configurations, estimated from the accelerations measured on June 16, 2018 (17h-18h), and on May 4, 2019 (4h-5h), are also presented. The first and fifth modes are antisymmetric, while the second and third modes are symmetric. Also, it is worth noting that the configuration of the fourth mode is clearly influenced by the horizontal cracking in the dam, resulting in the oscillation of the upper part of the dam.

Fig. 10 presents the comparison between the identified (circles) and computed (lines) natural frequencies over time, as well as the numerical frequency values and mode shapes calculated for reservoir levels at el. $285 \mathrm{~m}$ and $293.5 \mathrm{~m}$. Overall, this comparative analysis shows that there is a good agreement between experimental and numerical natural frequencies for the first five vibration modes, especially for higher water levels (given that the dam-tower interaction is not as significant). Regarding modal configurations, the shapes of modes 1 (antisymmetric), 2 (symmetric), and 3 (symmetric) are well reproduced by the model, while for modes 4 and 5 the mode shapes are swapped.

The results achieved in this application study allowed to show the usefulness of the SSHM installed in Cabril dam and the potential of the 3DFE program DamDySSA for simulating the dynamic response of the dam-reservoir-foundation system. Nevertheless, additional studies are proposed in the future to better understand the phenomena associated with the intake tower and with the horizontal cracking.

In order to show how the combined use of information extracted from continuous vibrations monitoring and of numerical results can be applied for vibration-based damage detection and hence to evaluate structural integrity of dams, an additional comparison is provided next (Fig. 11). The identified natural frequency values of the first mode (in red) are compared with the computed frequencies (in blue), using a) a linear reference model, without concrete damage, and b) a test model that simulates the scenario of evolutive damage during the period under analysis (2008-2020), considering a gradual damage variation between 0 and $5 \%$ over the whole dam body. Based on these results, it can be noted that the identified frequency values based on recent data are similar to the values in the early monitoring period. Furthermore, the differences between the identified frequencies and the values computed with the reference model without damage are the same (for similar water levels) over the whole monitoring period. Additionally, the frequency curves computed for a scenario of evolutive damage start to diverge from the identified frequencies. Therefore, it is possible to conclude that Cabril dam's structural integrity and thus its dynamic behavior has not been affected by the existing deterioration phenomena.

\subsection{Measured seismic response}

In this section theanalysis of the dynamic response of Cabril dam during a seismic event is presented. The seismic acceleration time histories recorded with the SSHM systemare compared with the numerical accelerations computed with DamDySSA4.0, in order to investigate how to simulate the measured dam response, namely, in order to investigate theaccelerations amplification from the dam-rock surface to the crest center point, and the required damping ratios to be used in the numerical model. 
The seismic response of Cabril is analyzed for an earthquake of magnitude 4.6 that occurred on September 4, 2018, with epicenter in the Peniche abyssal region (off the coast of Portugal), at $205 \mathrm{~km}$ from the dam. The seismic waves hit the dam from the west-northwest, approximately in the cross-valley direction. On that day, the water level was at $281.2 \mathrm{~m}, 15.8 \mathrm{~m}$ below the crest. This earthquake originated low amplitude vibrations in Cabril dam, from $1 \mathrm{mg}$ to $4 \mathrm{mg}$. As expected, the greater accelerations were recorded at the central upper part of the structure. The peak ground acceleration at the dam-rock interface $(1.31 \mathrm{mg})$ was recorded with the triaxial sensor at the right bank, while the maximum acceleration in the dam body (3.62 $\mathrm{mg}$ ) was measured at the top of central section, both in the upstream downstream direction - the amplification factor for accelerations (from the RB foundation to the crest center) was of around 2.8.

The FE seismic simulations were conducted using the previously shown numerical model, considering linear behavior, the reservoir level at el. $281 \mathrm{~m}$, and using the accelerations recorded at the right bank as the uniform seismic input. Fig. 12 shows the comparison between measured and computed accelerations at the upper gallery, in the central section of the dam, in the cross-valley, upstream-downstream, and vertical directions: these results show that there is a good fit with the computed accelerations in the upstream-downstream direction, while in the cross-valley and vertical directions the response is clearly overestimated. To achieve this results it was necessary to use a damping ratio of about $10 \%$ around the frequency band $2-3 \mathrm{~Hz}$ (first vibration modes), which is an unusually high value for an arch dam(Chopra \& Wang, 2012; Proulx \& Darbre, 2008; Robbe et al., 2017).

The provided results showed not only the reliability of Cabril dam's SSHM system to measure vibrations during seismic events, even those of lower amplitude induced by earthquakes with epicenters at a great distance from the dam site, but also the interest of seismic records measured on site to help in the validation and calibration of numerical models used for dam seismic behavior simulation. However, this comparative study also raised important questions on the numerical modelling of the linear seismic response of Cabril dam, namely in what concerns the need to use such a high damping value in order to reproduce the measured response. In the case of this dam, this difficulty may in fact be related to the use of an inadequate seismic input. In fact, it was used as input a seismic accelerogram measured in dam body near the RB upper dam-foundation interface. At the Cabril dam, an accelerometer has not yet been installed on the foundation, in the central section of the dam's base. In this context, in order to improve the characterization of the seismic action and allow a better understanding of the seismic behavior of the dam, it is planned to install a new triaxial accelerometer in the Cabril dam, on the foundation near the base of the dam, at the bottom of the valley.

\subsection{Non-linear seismic response. Safety assessment based on Endurance Time Analysis}

This section presents the most important results from a study on the non-linear seismic behavior of Cabril dam under intensifying seismic accelerations (Fig.13). , in order to evaluate the dam's performance 
based on an Endurance Time Analysis(Estekanchi et al., 2004). Therefore, the tensile and compressive damage distributions are analyzed at increasing levels of excitation to assess seismic safety (Fig.14).

The numerical simulations were carried out using DamDySSA and the non-linear version of the model presented above, considering damage in concrete and joint movements. The seismic response was calculated for the dynamic load combination involving the dam's self-weight (SW), the hydrostatic pressure for full reservoir (HP297), and an intensifying seismic load (SeismicL) applied in the upstreamdownstream direction. For seismic input, an ETA acceleration time history provided in (Salamon et al., 2021), with increasing peak accelerations $\left(a_{p}\right)$ from 0 to $1.5 \mathrm{~g}$ (at $15 \mathrm{~s}$ ), was used (Fig. 13).

In what concerns the safety assessment, an empirical evaluation of the dam's seismic performance was considered. In this study, the seismic safety was verified at the end of each second of the numerical simulation, based on the damage distributions at both upstream and downstream faces, and along the thickness, until an endurance limit was reached. The criterion adopted here respects to the damage extension, particularly along the thickness of the dam's cantilevers: the occurrence of considerable areas of the dam in which tensile damage propagates across the whole thickness is considered inacceptable.

For the case of Cabril dam, the referred endurance limit was of $6 \mathrm{~s}\left(a_{p}=0.6 \mathrm{~g}\right)$, since that at this excitation level significant tensile damage stars to cover an extensive area of the downstream face(Fig. 14), which start to propagate along the thickness of some of the shorter, lateral cantilevers. there is an increase of tensile damage at the upstream face and that concrete failure starts to propagate from upstream to downstream in some areas of the upper part of the dam, even in the central cantilevers. However, it is worth emphasizing that compressive damages only appear after $10 \mathrm{~s}\left(\mathrm{a}_{\mathrm{p}}=1 \mathrm{~g}\right)$., when the first concrete failure under compression occurs at the top of the central cantilevers, and increase progressively as shown in Fig.14, until $14 \mathrm{~s}\left(\mathrm{a}_{\mathrm{p}}=1.4 \mathrm{~g}\right)$.

In synthesis, the results of the non-linear seismic response of Cabril dam obtained with the Endurance Time Analysis allowed to conclude that Cabril dam presents a very good performance for high excitation levels, corresponding to peak ground accelerations that could perfectly be prescribed for seismic safety verification studies. The Cabril dam is capable of withstanding seismic accelerations 2.5 times greater than those defined for the Maximum Design Earthquake (MDE: $a_{p}=0.2 \mathrm{~g}$ ) without severe tension damage and 7 times greater than that defined for the MDE without severe compressive damage (no collapse).

\section{Cahora Bassa Dam}

\subsection{Dam characteristics and installed SSHM system}

The Cahora Bassa dam, located on the Zambezi River in western Mozambique, near the village of Songo (Fig. 15), came into operation in late 1974. It is a $170 \mathrm{~m}$ high thindouble curvature arch dam with a crest $303 \mathrm{~m}$ in length, at an elevation of $331 \mathrm{~m}$. The thickness of the central section varies from 23 at the base 
to $4 \mathrm{~m}$ at the crest, which has the particularity of being half hollow. The dam was built on a rock mass of very good quality gneiss granite. It has a surface spillway in the middle of the crest and eight half-height spillways, with a combined capacity of $14000 \mathrm{~m}^{3}$. On the upstream face there are several concrete ribs that extend from the crest to the top of the half-height spillways, which are used to raise and lower their gates. The hydroelectric plant, located on the south bank of the river, is the largest hydroelectric project in southern Africa.

A process of concrete swelling was detected in the 1980s. Upward and upstream evolutive displacements have been measured and a typical hexagonal crack pattern due to swelling is visible on the crest surface (Fig.15).

Cahora Bassa dam's SSHM system was installed in 2010 to allow the continuous evaluation of the dam's behavior for normal operating conditions, under ambient/operational vibrationsand for seismic events. So, the system is prepared to provide useful experimentalinformation for structural health monitoring and for seismic control. Acceleration records are collected in various locations, namely, in dam body near the crestand near the base of the central section, and in the foundation,near the dam-foundation interface, in both banks, (Fig. 16). Thus, the monitoring system comprises 10 uniaxial accelerometers (EpiSensor ESU2) and 3 triaxial accelerometers (EpiSensor ES-T) from Kinemetrics. The uniaxial sensors, which measured accelerations in the radial direction, are installed in the upper gallery (at el. $326 \mathrm{~m}$ ). As for the triaxial sensors, two are located in the right and left banks, in the rock, and the third one is position at the downstream base of the dam, in the central section. To achieve a system with a high dynamic range, extremely low noise sensors with a full-scale recording range of $\pm 1 \mathrm{~g}$ were used. All sensors are connected through a local optical fiber network to a single 24-channel data acquisition Granite unit from Kinemetrics (24 bit). To summarize, 19 acceleration time histories are continuously recorded, every hour, at a sampling rate of $50 \mathrm{~Hz}$, and then transmitted to the computer server in the dam's control center.

\subsection{Numerical Model of Cahora-Bassa dam}

The numerical simulations for Cahora Bassa dam are performed using the program DamDySSA and the model of the dam-reservoir-foundation system shown in Fig. 17. The dam concrete and the foundation rock are isotropic materials, with the same Young's modulus E $=40 \mathrm{GPa}$ and Poisson's ratio $\mathrm{v}=0.2$, and considering a $25 \%$ increase of $E$ for dynamic analysis. The reservoir water is a compressible fluid, assuming an average pressure wave propagation velocity $c_{W}=1500 \mathrm{~m} / \mathrm{s}$ since the water temperature in the reservoir showed seasonal oscillations between $20-30^{\circ} \mathrm{C}$. The current model of Cahora Bassa dam does account for the concrete ribs at the upstream face, and it does not incorporate the surface and halfheight spillways. The version of the model used for non-linear seismic calculations considers the nonlinear behavior of concrete up to failure, using a strain-softening constitutive damage law with tensile strength $\mathrm{f}_{\mathrm{t}}=3 \mathrm{MPa}$ and compressive strength $\mathrm{f}_{\mathrm{c}}=-30 \mathrm{MPa}$, and it incorporates all vertical contraction joints and the surface along the dam-foundation interface, assuming appropriate normal and shear stiffness values and stress-displacement laws to account for opening/closing and sliding movements.

Page $16 / 42$ 


\subsection{Modal Analysis. Evolution of natural frequencies over time}

This section is focused on analyzing the dynamic behavior of Cahora Bassa dam in normal operating conditions, between August 2010 and June 2020. Modal parameters are extracted from monitoring data using DamModalID, and the dynamic calculations are performed using DamDySSA. As in the case of Cabril dam, the goal is to investigate the influence of water level variations on the dynamic behavior of the dam-reservoir-foundation system and show how the combined use of experimental and numerical frequencies can be used for damage detection.

Fig. 18 presents the comparison between the automatically identified natural frequencies over time (circles), during the whole monitoring period with a reservoir level variation from el. $312 \mathrm{~m}$ to el. $326 \mathrm{~m}$, and the numerical frequency curves, obtained in various numerical simulations with different reservoir levels, for the first five vibration modes. The calculated frequencies and 3D modal configurations for the reservoir level at el. $326 \mathrm{~m}$ are also shown: modes 1 is antisymmetric, while all others are symmetric.

As expected, once again the provided results show that the water level variations have a significant influence on the dynamic response of the dam, as indicated by the correlation between the water level and the frequency values. For example, the natural frequencies vary from 1.95 to $1.78 \mathrm{~Hz}$, for the first mode, and from 2.4 to $2.16 \mathrm{~Hz}$, for the second mode. In comparison with Cabril dam, it should be mentioned that for Cahora Bassa dam the variations in the frequency values for modes with similar frequencies are lower given that the water level variations are not as significant. Moreover, in Cahora Bassa dam, the temperature semi-amplitude is around $\pm 4^{\circ} \mathrm{C}$ throughout the year, and thus the influence of thermal variations was not considered here. Furthermore, the figure displays the identified frequencies associated with the power groups, with frequencies at 1.79 and at $3.57 \mathrm{~Hz}$.

The provided results also show that it was possible to reach a good agreement between experimental and numerical frequency values for Cahora Bassa dam, namely for the first three and the fifth modes. This comparison improves as the water level increases, but even for lower reservoir levels the observed differences are not greater than $0.1 \mathrm{~Hz}$. The only exception here is the fourth mode, for which the agreement is not so good. Therefore, further analyses are proposed in order to better comprehend the evolution of the fourth mode's frequencies, if possible, using a more advanced FE model of the dam that incorporates the upstream face concrete ribs, the half-height spillways, and the half-hollow crest.

In the scope of structural health monitoring of Cahora Bassa dam, Fig. 19 presents the comparison between the identified natural frequencies for the first mode (in red) and the computed frequency curves (in blue), considering a linear reference model without damage (Fig.19a), and a test model that simulates a progressive damage evolution from 0 to 5\%, over the whole dam body (Fig.19b). By analyzing the results for a decade of vibrations monitoring, it is possible to see that recent experimental frequencies are similar to those obtained in the first monitoring years, for the same water levels. In addition, considering a model without evolutive damage, the experimental/numerical relation for the natural frequencies is stable 
during the last decade, unlike what is obtained when an increasing damage model was assumed. So,it can be concluded that the concrete swelling process is not significantly affecting the dam's structural integrity, since its dynamic behavior has not changed in a noticeable way over the past ten years.

\subsection{Measured seismic response}

This section analyzes the seismic response of the Cahora Bassa dam, measured during an earthquake that occurred on June 21, 2017 (Fig. 20). It was estimated that the distance to the epicenter would be approximately $32 \mathrm{~km}$. Seismic waves reached the west-northwest dam site, between the upstreamdownstream and cross-valley directions. The reservoir level was at el. $319.7 \mathrm{~m}$ (11.3 m below the crest) that day. This was a low-intensity, near-seismic event that caused low amplitude vibrations in the dam (with a maximum of about $40 \mathrm{mg}$ ). The maximum ground accelerations recorded at the downstream base were $22 \mathrm{mg}$ in thecross-valley direction, $9 \mathrm{mg}$ in the upstream-downstream direction, and $6 \mathrm{mg}$ in the vertical direction. The peak acceleration recorded at the upper gallerywas of $38 \mathrm{mg}$, resulting in a base to top acceleration amplification factor of about 4.2, in the upstream-downstream direction.

The seismic calculations were performed using the numerical model of the dam shown above (Fig.17), assuming a linear elastic behavior, the water level in el. $319 \mathrm{~m}$, and using the acceleration records measured at the base of the central section (bottom of the valley) as the seismic input. In Fig. 20 the good agreement between the radial acceleration measured in the upper gallery and the calculated accelerations is shown. Unlike the study on the Cabril dam where a high damping ratio of $10 \%$ was used (the seismic accelerations measured on the right bank were used as input), in the case of the Cahora Bassa dam this good measured/calculated agreement was reached considering a reasonable damping ratio of $1 \%$ (for the lower natural frequencies).

The analysis presented here shows the capacity of the SSHM system installed at the Cahora Bassa dam to measure vibrations induced by seismic events and the interest of measured in-situ accelerations to validate and calibrate the numerical models, which are later used in seismic safety verification studies.

\subsection{Non-linear seismic response. Safety assessment based on Endurance Time Analysis}

In this section, the non-linear seismic response of the Cahora Bassa dam under increasing amplitude seismic accelerations is presented, with the aim of evaluating the performance of the dam based theEndurance Time Analysis method(Estekanchi et al., 2004). The seismic safety assessment is based on the assessment of tensile and compressive damage distributions. With regard the evaluation of the dam's safety, the same criteria considered before for the Cabril dam are used here to define the endurance limit. 
The non-linear calculations were performed using DamDySSA4.0 and a non-linear model of Cahora Bassa dam, considering concrete damage and joint movements. The seismic response was computed for the load combination (Fig. 21) with the dam's self-weight (SW), the hydrostatic pressure for full reservoir (HP331), and an increasing amplitude seismic accelerogram (SeismicL) applied in the upstreamdownstream direction.

For the case of the Cahora Bassa dam, the endurance performance is $5 \mathrm{~s}(\mathrm{ap}=0.5 \mathrm{~g}$ ), as for this excitation level the tensile damage is mostly superficial, although it starts to occur in a significant area of the surface at downstream (Fig. 22). However, at higher excitation levels, tensile damage extends over significant areas of the upstream and downstream faces and starts to propagate through the thickness of most cantilevers, which would not be acceptable. Also, at $t=5 \mathrm{~s}$, there is no noteworthy compressive damage. However, high compressive damage starts to occur after $7 \mathrm{~s}$, and progressively increases up to $10 \mathrm{~s}(\mathrm{ap}=1 \mathrm{~g})$, when the compressive rupture of the concrete crosses the entire thickness in the upper zone of the central cantilevers. In short, the results achieved in the Endurance Time Analysis of the Cahora Bassa Dam allow us to conclude that this dam has a very good seismic performance, even for excitation levels up to 5 times higher than the prescribed Maximum Design Earthquake (MDE), which corresponds to a peak ground acceleration of $0.1 \mathrm{~g}(\mathrm{Li}-\mathrm{EDF}-\mathrm{KP}, 2001)$.

\section{Conclusions}

This work has shown that the use of SSHM systems in the safety control of large concrete dams allows to obtain results of great interest for monitoring deterioration processes, for the characterization of the seismic response of dams, and for studying the dynamic behavior of dam-reservoir-foundation systems.

The efficiency and effectiveness of these SSHM systems obviously depends on the in-situ installation of adequate equipment for measuring, transmitting and storing the data collected continuously (with sampling frequencies of $50 \mathrm{~Hz}$ or higher) and, above all, on the use of appropriate software, namely: (i) to manage, store, and analyze collected data, considering the need to automatically distinguish vibrations due to ambient/operational excitations from those induced by seismic actions; (ii) for automatic modal analysis, with a view to identify, at each hour, the natural frequencies and corresponding modal configurations (and, if possible, modal damping), in order to correlatethe identified values with the changes in the reservoir water level and, eventually, with the annual temperature variations; and (iii) for automatic comparison between experimental results, obtained from automatic modal identification and automatic detection of seismic vibrations, and numerical results, predicted based on finite element models specifically developed to simulate the dynamic dam-foundation-reservoir interaction.

Complete studies on the dynamic behavior of Cabril and Cahora Bassa dams, two large arch dams under continuous dynamic monitoring since 2008 and 2010, respectively, were presented. The SSHM data analysis was performed using software developed for automatic modal identification (DamModalID1.0) and for automatic detection of seismic vibrations (DamSeismicVibID1.0). The numerical calculations were carried out using a 3DFE program (DamDySSA4.0) developed for dynamic analysis of concrete 
dams, based on a coupled formulation in displacements and pressures, which includes three modules for (1) complex modal analysis of the global system, using a coupled state-space approach, (2) for linear seismic analysis, using a coupled time-stepping procedure, and(3) for non-linear seismic analysis, considering joint movements and concrete failure using an isotropic damage model of two independent damage variables (tensile, $d^{+}$, and compressive, $d^{-}$, damage).

The most significant and updated results from continuous vibrations monitoring of Cabril dam and Cahora Bassadam over the last decade were presented here and compared with results from FE analyses. Based on the evolution of the natural frequencies over time, it was possible to note that the dynamic behavior of both dams is clearly affected by the reservoir water level. Also, the presented comparative studies allowed to demonstrate how the combination of results extracted from SSHM data and results from FE calculations can be of great use for safety control, particularly for structural health monitoring, by applying vibration-based damage detection methodologies. In both cases, the good agreement achieved between the identified frequenciesand the frequencies computed using reference models (without damage) enabled to conclude that the existing deterioration phenomena have not significantly affected Cabril and Cahora Bassa dam's dynamic performance in normal operating conditions over the last decade. Regarding the seismic response during earthquake events, the comparison between measured and computed accelerations was important to further investigate the dams' behavior when subjected to lower intensity earthquakes, as well as to calibrate the damping parameters required as input in the FE models.

Furthermore, the main results of a non-linear seismic analysis of Cabril and Cahora Bassa dams were presented, based on the Endurance Time method, for a load combination involving the dam's self-weight, the hydrostatic pressure for full reservoir and an intensifying seismic load. The non-linear seismic simulations were carried out considering the non-linear concrete behavior and opening/closing and sliding joint movements. Overall, the numerical results showed that important tensions occurred in the central upper part of the downstream face, as well as along the upstream base, resulting in significant tensile damagein these zones. Regarding the seismic structural safety, the evaluation of the seismic performance of these two large arch dams allowed to conclude that Cabril dam (medium seismicity zone, MDE: $0.2 \mathrm{~g}$ ) and Cahora Bassa dam (low seismicity zone: MDE: $0.1 \mathrm{~g}$ ) present a very good resistant capacity to withstand peak ground seismic accelerations of about $0.6 \mathrm{~g}$ and $0.5 \mathrm{~g}$, respectively, without tensile damage occurring across the entire thickness of the cantilevers. Moreover, both dams also support seismic accelerations of about $1.4 \mathrm{~g}$ and $1.0 \mathrm{~g}$, respectively, without presenting severe compressive damage across their entire thickness.

Finally, with this paper it was possible (i) to emphasize the advantages of using SSHM systems, complemented with suitable software for monitoring data analysis (DamModalID1.0 and DamSeismicVibID1.0), and of advanced programs for FE analysis to study the dynamic behavior of arch dams over time and thus provide useful information for supporting safety control and structural health monitoring; and (ii) to demonstrate the potential of DamDySSA4.0 for predicting the non-linear seismic behavior of concrete dams and to support seismic safety verifications. 


\section{Declarations}

\section{ACKNOWLEDGMENT}

The authors thank Eletricidade de Portugal (EDP) and Hidroeléctrica de Cahora Bassa (HCB) for their efforts in the installation and maintenance of the SSHM systems of the Cabril and Cahora Bassa dams, respectively, and the Portuguese Foundation for Science and Technology (FCT) for the initial funding for the acquisition of equipment for the Cabril Dam (REEQ / 815 / ECM / 2005), for the funding of the SFRH/BD/116417/2016 doctoral scholarship and for the funding of the Project "Seismic and Structural Health Monitoring for Large Concrete Dams (SSHM4Dams)", PTDC / ECI-EGC / 5332/2020.

\section{COMPLIANCE WITH ETHICAL STANDARDS}

The authors declare that they have no conflict of interest

\section{References}

1. Alegre A, Carvalho E, Matsinhe B, Mendes P, Oliveira S, Proença J (2019) Monitoring vibrations in large dams. HYDRO 2019 - Concept to Closure: Practical Steps, Porto, Portugal

2. Alegre A, Oliveira $S$ (2020) Non-linear seismic analysis of arch dams considering joint movements and a concrete damage model. 4th Dam World Conference, LNEC

3. Alegre A, Oliveira S, Carvalho E, Matsinhe B, Mendes P, Proença J (2020) Seismic and Structural Health Monitoring of Cahora Bassa dam and Non-Linear Seismic Analysis. HYDRO 2020 - Strategies for Future Progress, Online event

4. Alegre A, Oliveira S, Espada M, Câmara R (2019) Seismic analysis of an ultra-high arch dam using the 3DFE program DamDySSA3.0. Study on the influence of the reservoir water level. Revista Portuguesa de Engenharia de Estruturas., Série III(11), 115-126, ISSN 2183-8488

5. Alegre A, Robbe E, Oliveira S (2020) Seismic analysis of Cabril dam. Measured response and comparison with numerical results from Code_Aster and DamDySSA. 4th Dam World Conference, LNEC

6. ANSYS Inc (2020) Ansys. ANSYS Inc., Canonsburg

7. Belytschko T (1980) Fluid-structure interaction. Comput Struct 12:459-469

8. Bouaanani N, Lu FY (2009) Assessment of potential-based fluid finite elements for seismic analysis of dam-reservoir systems. Comput Struct 87:206-224

9. Brincker R, Ventura C (2015) Introduction to Operational Modal Analysis. John Wiley \& Sons

10. Bukenya P, Moyo P (2017) Monitoring the structural behaviour of concrete arch dams: the case of Roode Elsberg dam, South Africa. SANCOLD Conference 2017: Management of Dams and Reservoirs in Southern Africa, Centurion, Tshwane, South Africa

11. Bukenya P, Moyo P, Beushausen H, Oosthuizen C (2014) Health monitoring of concrete dams: a literature review. Journal of Civil Structural Health Monitoring 4(4):235-244. 
https://doi.org/10.1007/s13349-014-0079-2

12. Câmara R (1989) Modelos para estudo do comportamento dinâmico de barragens de betão pelo método dos elementos finitos [Models for studying the dynamic behaviour of concrete dams based on the finite element method]. Specialist Thesis, LNEC

13. Carvalho E, Matsinhe B (2014) First steps on automatic data acquisition and analysis system in Cahora Bassa dam. HYDRO 2014, Como, Italy

14. Carvalho E, Tembe I (2012) On-Line Dynamic Monitoring of Cahora Bassa dam. International Symposium on Dams for a Changing World, Kyoto, Japan

15. Carvalho E, Valentim N, Oosthuizen C (2014) On-Line Dynamic Monitoring of Cahora Bassa dam ... the next level. International Symposium on Dams for a Changing World, Bali, Indonesia

16. Cervera M, Oliver J, Faria R (1995) Seismic evaluation of concrete dams via continuum damage models. Earthquake Engineering Structural Dynamics 24(9):1225-1245.

https://doi.org/10.1002/eqe.4290240905

17. Chen H (1994) Model test and program verification on dynamic behaviour of arch dam with contraction joints. Report No. SVL-94/2 IWHR

18. Chopra AK, Wang J-T (2010) Earthquake response of arch dams to spatially varying ground motion. Earthquake Engineering Structural Dynamics 39:887-906. https://doi.org/10.1002/eqe.974

19. Chopra AK, Wang J-T (2012) Comparison of recorded and computed earthquake response of arch dams. 15th World Conference on Earthquake Engineering, Lisbon, Portugal

20. Clough RW (1980) Non-linear mechanisms in the seismic response of arch dams. International Research Conference on Earthquake Engineering, Skopje, Yugoslavia

21. Clough RW, Penzien J (2003) Dynamics of Structures. Third). Computers \& Structures, Inc.

22. Espandar R, Lotfi V (2003) Comparison of non-orthogonal smeared crack and plasticity models for dynamic analysis of concrete arch dams. Comput Struct 81(14):1461-1474. https://doi.org/10.1016/S0045-7949(03)00083-X

23. Estekanchi HE, Vafai A, Sadeghazar M (2004) Endurance Time Method for Seismic Analysis and Design of Structures. Scientia Iranica 11(4):361-370

24. Faria R, Oliver J, Cervera M (1998) A strain-based plastic viscous-damage model for massive concrete structures. Int J Solids Struct 35(14):1533-1558. https://doi.org/10.1016/S00207683(97)00119-4

25. Fenves GL, Mojtahedi S, Reimer RB (1989) ADAP-88: a computer program for non-linear earthquake analysis of concrete arch dams. Report No. UCB/EERC-89/12, University of California, Berkeley, California

26. Fenves GL, Mojtahedi S, Reimer RB (1992) Effect of contraction joints on earthquake response of an arch dam. J Struct Eng 118:1039-1055

27. Fok KL, Hall JF, Chopra AK (1986) EACD-3D: a computer program for three-dimensional earthquake analysis of concrete dams. Report No. UCB/EERC-86/09, University of California, Berkeley, California 
28. Gomes JP, Magalhães F, Monteiro GS, Palma J, Pereira S, Silva Matos D (2018) Seismic monitoring system of Baixo Sabor scheme for structural dynamic behavior monitoring and risk management. 26th ICOLD Congress on Large Dams, Vienna, Austria

29. ICOLD (2018) Bulletin 158: Dam surveillance guide (p. International Comission on Large Dams)

30. ICOLD (2019) World Declaration on Dam Safety (p. International Comission on Large Dams)

31. Lau DT, Boruziaan B, Razaqpur AG (1998) Modelling of contraction joint and shear sliding effects on earthquake response of arch dams. Earthquake Eng Struct Dynam 27:1013-1029

32. Lemos JV (1998) Development of an arch dam analysis module for the program 3DEC. LNEC Report

33. Li- EDF-KP (2001) Seismic Hazard Assessment of Cahora Bassa extension and Mepanda Uncua hydroelectric projects on Zambezi river/Mozambique

34. Li H-N, Li D-S, Ren L, Yi T-H, Jia Z-G, LI K-P (2016) Structural health monitoring of innovative civil engineering structures in Mainland China. Structural Monitoring Maintenance 3(1):1-32. https://doi.org/10.12989/smm.2016.3.1.001

35. Liao ZP, Wong HL, Yang BP, Yuan YF (1984) A transmitting boundary for transient wave analyses. Sci Sinica 27(10):1063-1076

36. Limongelli MP (2020) SHM for informed management of civil structures and infrastructure. Journal of Civil Structural Health Monitoring 10(5):739-741. https://doi.org/10.1007/s13349-020-00439-8

37. Limongelli MP, Çelebi M (eds) (2019) Seismic Structural Health Monitoring. Springer International Publishing, https://doi.org/10.1007/978-3-030-13976-6

38. Lysmer J, Kuhlemeyer RL (1969) Finite dynamic model for infinite media. Journal of the Engineering Mechanics Division (ASCE) 95:759-877

39. Mendes P (2010) Observação e análise do comportamento dinâmico de barragens de betão [Observation and analysis of concrete dams dynamic behaviour]. PhD Thesis, University of Porto (FEUP/LNEC)

40. Mendes P, Oliveira S (2009) Influence of the dynamic behaviour of the intake tower on modal identification of Cabril dam. 3rd International Operational Modal Analysis Conference (IOMAC'09), Ancona, Italy

41. Niwa A, Clough RW (1982) Non-linear seismic response of arch dams. Earthquake Eng Struct Dynam 10:267-281

42. Oliveira S (2002) "Continuous monitoring systems for the dynamic performance assessment of arch dams"'. Sub-program D, in Study of evolutive deterioration processes in concrete dams. Safety control over time. National Program for Scientific Re-equipment funded by FCT, LNEC-FEUP.

43. Oliveira S, Alegre A (2019) Seismic and Structural Health Monitoring of Dams in Portugal. In M. P. Limongelli \& M. Çelebi (Eds.), Seismic Structural Health Monitoring (pp. 87-113). Springer International Publishing. https://doi.org/10.1007/978-3-030-13976-6_4

44. Oliveira S, Alegre A (2020) Seismic and structural health monitoring of Cabril dam. Software development for informed management. Journal of Civil Structural Health Monitoring 10(5):913- 
925. https://doi.org/10.1007/s13349-020-00425-0

45. Oliveira S, Alegre A (2018) Vibrations in large dams. Monitoring and modelling. 26th ICOLD Congress on Large Dams, Vienna, Austria

46. Oliveira S, Espada M, Câmara R (2012) Long-term dynamic monitoring of arch dams. The case of Cabril dam, Portugal. 15th World Conference on Earthquake Engineering, Lisbon, Portugal

47. Oliveira S, Faria R (2006) Numerical simulation of collapse scenarios in reduced scale tests of arch dams. Eng Struct 28(10):1430-1439

48. Oliveira S, Mendes P, Garrett A, Costa O, C., \& Reis J (2011) Long-term dynamic monitoring systems for the safety control of large concrete dams. The case of Cabril dam, Poirtugal. 6th International Conference on Dam Engineering, Lisbon, Portugal

49. Oliveira S, Silvestre A, Espada M, Câmara R (2014) Modeling the dynamic behavior of dam-reservoirfoundation systems considering generalized damping. Development of a 3DFEM state formulation. International Conference on Structural Dynamic EURODYN, Porto, Portugal

50. Pedro JO (1999) Safety and Performance of Arch Dams. In J. O. Pedro (Ed.), Arch Dams. Designing and monitoring for safety. International Centre for Mechanical Sciences (Courses and Lectures), vol 367 (pp. 1-78). Springer Vienna. https://doi.org/10.1007/978-3-7091-2488-8_1

51. Pedro JO, Câmara R (1986) Coupled models for dynamic analysis of arch dams. 8th European Conference on Earthquake Engineering, Lisbon, Portugal

52. Pereira S, Magalhães F, Gomes JP, Cunha Á, Lemos JV (2017) Installation and results from the first 6 months of operation of the dynamic monitoring system of Baixo Sabor arch dam. 10th International Conference on Structural Dynamics EURODYN 2017, Rome, Italy

53. Pereira S, Magalhães F, Gomes JP, Cunha Á, Paixão J, Lemos JV (2021) Continuous Dynamic Monitoring System of Foz Tua Arch Dam: Installation and First Results. EWSHM 2020: European Workshop on Structural Health Monitoring, 316-326. https://doi.org/10.1007/978-3-030-64594-6_32

54. Proulx J, Darbre GR (2008) Earthquake response of large arch dams. Observational evidence and numerical modelling. 14th World Conference on Earthquake Engineering, Beijing, China

55. Ramos JM (1994) Fiabilidade e monitoramento de barragens de betão [Reliabilty and monitoring of concrete dams]. Research program, LNEC, Portugal

56. Robbe E, Kashiwayanagi M, Yamane Y (2017) Seismic analyses of concrete dam, comparison between finite-element analyses and seismic records. 16th World Conference on Earthquake Engineering, Santiago, Chile

57. Salamon J, Hariri-Ardebili MA, Malm R, Wood C, Faggiani G (2021) Numerical Analysis of Dams. Theme A: Seismic Analysis of Pine Flat Concrete Dam. In G. Bolzon, D. Sterpi, G. Mazzà, \& A. Frigerio (Eds.), 15th ICOLD International Benchmark Workshop (Vol. 91, p. Milan, Italy). Springer International Publishing. https://doi.org/10.1007/978-3-030-51085-5

58. Sani AA, Lofti V (2010) Dynamic analysis of concrete arch dams by ideal-coupled modal approach. Eng Struct 32:1377-1383 
59. Sevim B, Altunışık AC, Bayraktar A, Akköse M, Calayir Y (2011) Water length and height effects on the earthquake behavior of arch dam-reservoir-foundation systems. KSCE J Civ Eng 15(2):295-303

60. Silva Matos D, Tavares de Castro A, Gomes A, Figueiredo N, J (2019) The behaviour of Foz Tua dam during the first filling of the reservoir and its first years of operation. HYDRO 2019, Porto, Portugal

61. Ueshima T, Shiojiri H, Kanazawa K (2017) Structural health monitoring of an aged arch dam using long-term continuous observation of ambient vibration/seismic motion. 16th World Conference on Earthquake Engineering, Santiago, Chile

62. Valliappan S, Yazdchi M, Khalili N (1999) Seismic analysis of arch dams - a continuum damage mechanics approach. International Journal of Numerical Methods in Engineering 45(11):1695-1724

63. Veletsos A, Ventura C (1986) Modal analysis of non-classically damped linear systems. Earthquake Eng Struct Dynam 14:217-243

64. Wang J-T, Chopra AK (2008) A computer program for three-dimensional analysis of concrete dams subjected to spatially-varying ground motion. Report No. UCB/EERC-2008/04, Earthquake Engineering Research Center. University of California, Berkeley

65. Wang J-T, Chopra AK (2010) Linear analysis of concrete arch dams including dam-water-foundation rock interaction considering spatially varying ground motions. Earthquake Engineering Structural Dynamics 39(7):731-750. https://doi.org/10.1002/eqe.968

66. Wang J-T, Lv D-D, Jin F, Zhang C (2013) Earthquake damage analysis of arch dams considering dam-water-foundation interaction. Soil Dyn Earthq Eng 49:64-74. https://doi.org/10.1016/j.soildyn.2013.02.006

67. Westergaard HM (1933) Water pressures on dams during earthquakes. Transactions (ASCE) 98:418472

68. Wieland M (2016) Safety Aspects of Sustainable Storage Dams and Earthquake Safety of Existing Dams. Engineering 2(3):325-331. https://doi.org/10.1016/J.ENG.2016.03.011

69. Zhang C, Pan J, Wang J-T (2009) Influence of seismic input mechanisms and radiation damping on arch dam response. Soil Dyn Earthq Eng 29(9):1282-1293

70. Zienkiewicz OC, Bettess P (1978) Fluid-structure dynamic interaction and wave forces. An introduction to numerical treatment. International Journal on Numerical Methods in Engineering $13: 1-16$

71. Zienkiewicz OC, Taylor RL, Fox DD (2013) The Finite Element Method for Solid and Structural Mechanics (Butt (Ed.); 7th ed.). Butterworth-Heinemann, Elsevier Ltd

72. Zienkiewicz OC, Taylor RL, Zhu JZ (2013) The Finite Element Method: Its Basis and Fundamentals (7th ed.). Elsevier Butterworth-Heinemann. https://doi.org/10.1016/b978-1-85617-633-0.00020-4

\section{Figures}


Pacoima dam (1929), California, USA, 113 m high

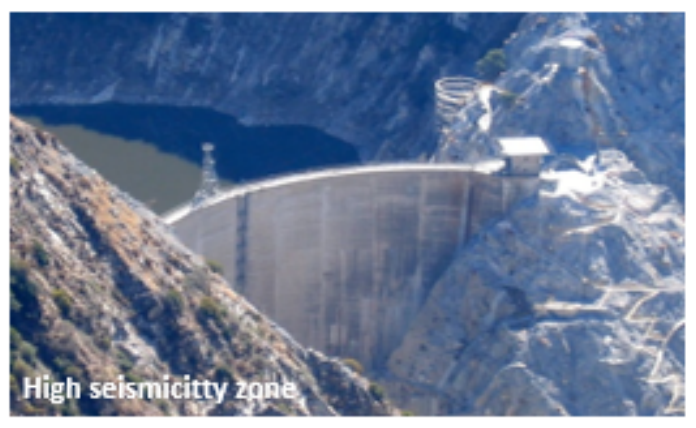

Cahora Bassa dam (1974), Mozambique, $170 \mathrm{~m}$ high

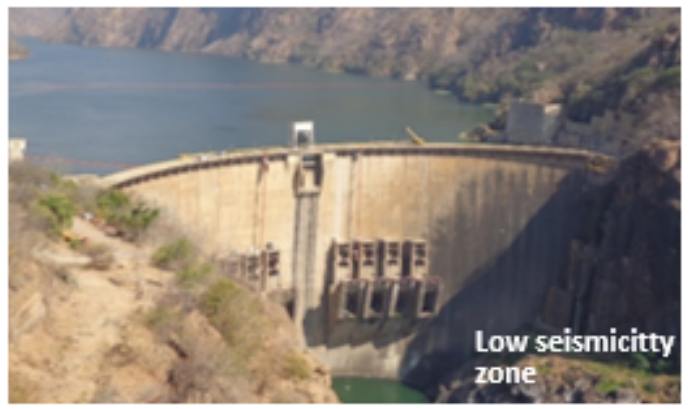

Cabril dam (1954), Portugal, $132 \mathrm{~m}$ high

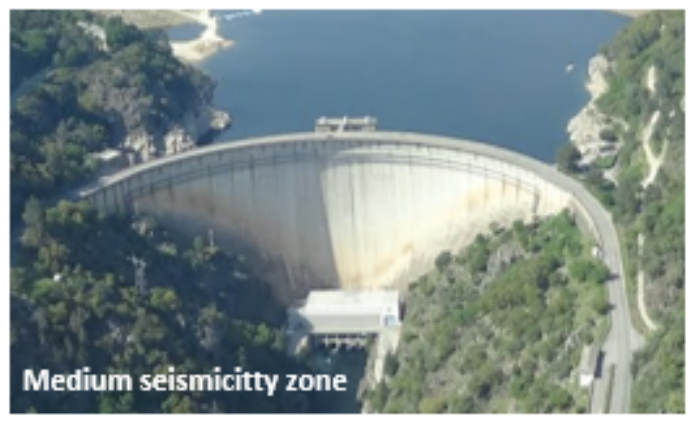

Jinping-I dam (2013), Sichuan, China, 305 m high

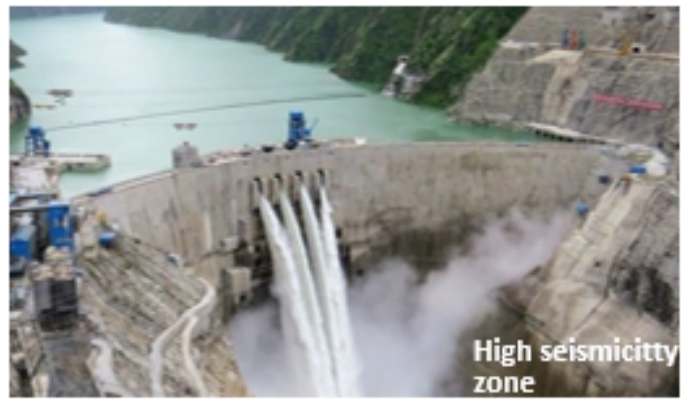

Figure 1

Large arch dams located in seismic regions (USA, Portugal, Mozambique and China). 


\section{Hardware}

Accelerometers, digitizers, data

- concentrators, electrical/optical signal converters, data transmission cables

- Local server, hard disc

- Internet connection, and remote access equipment
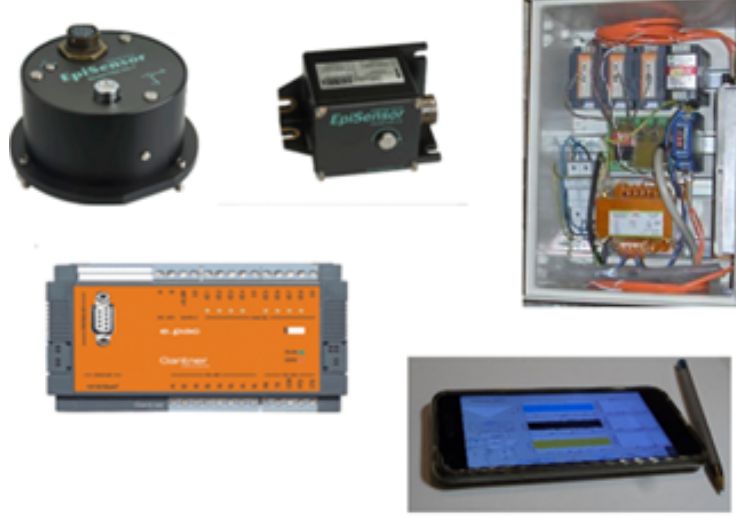

Software

- Data acquisition and management

- Data analysis

- Automatic modal identification

- Automatic identification of seismic vibrations
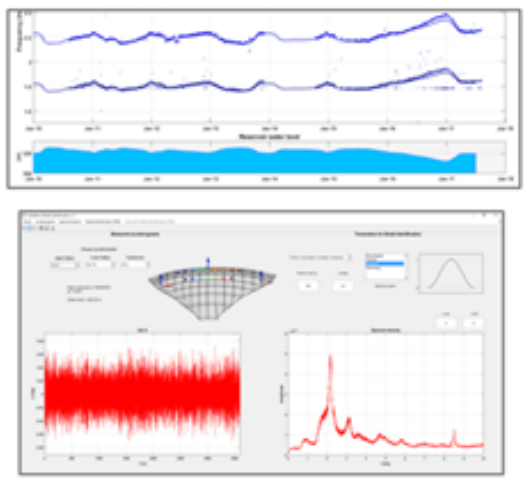

- Analysis with FE models

- Complex modal analysis (natural frequencies, nonstationary vibration modes)

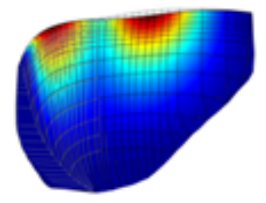

- Linear and non-linear seismic analysis

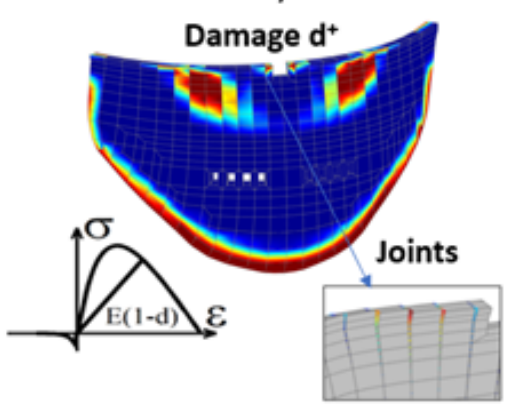

\section{Comparison between experimental and numerical results}

Evolution over time of the natural frequencies
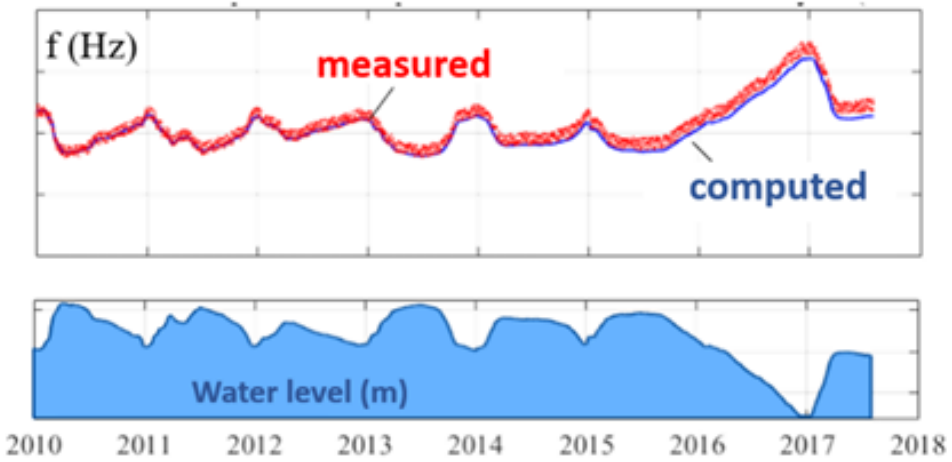

\section{Seismic accelerations}

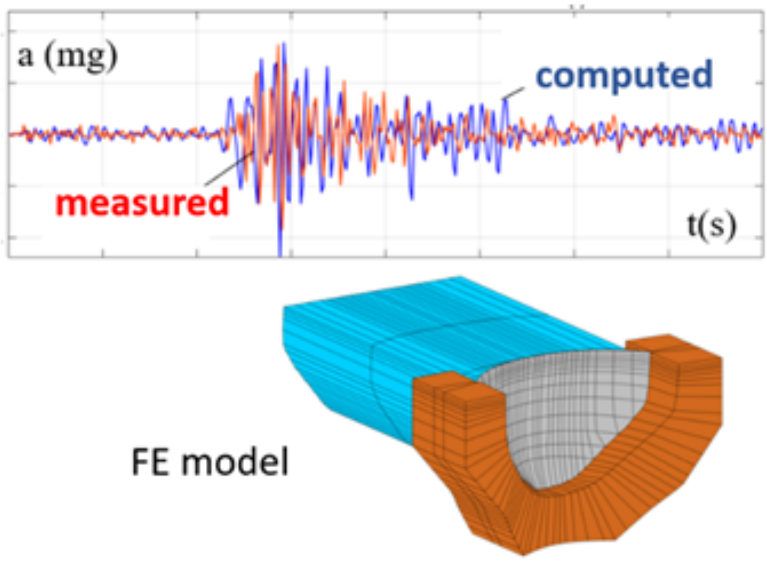

\section{Figure 2}

Main components of an SSHM system for large dams. Graphical representations adopted for comparison between experimental and numerical results 


\section{SOFTWARE FOR MONITORING DATA ANALYSIS}

DamModalID. Modal identification. Interactive and automatic modules
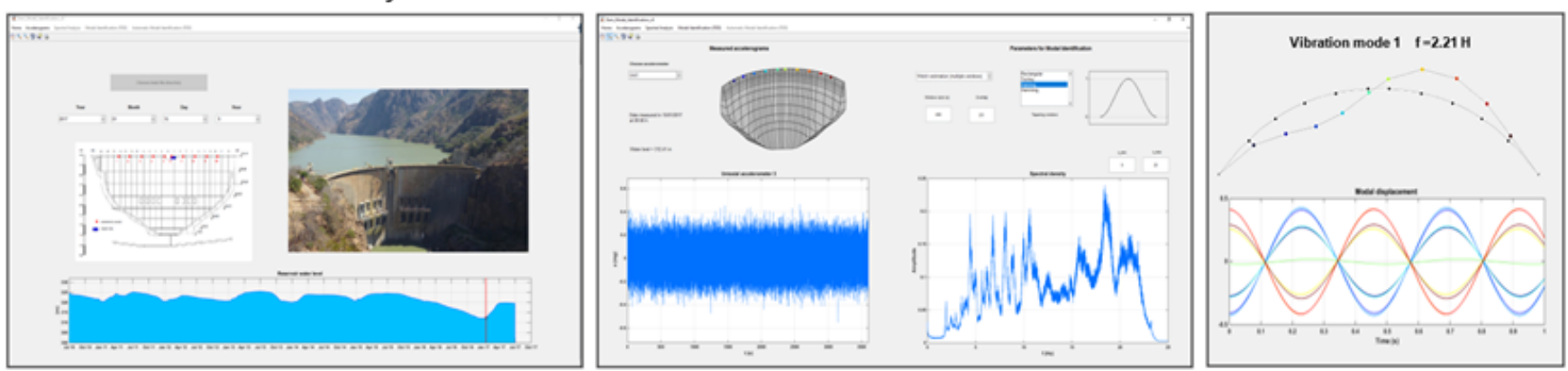

DamSeismicVibID. Automatic identification of seismic vibrations

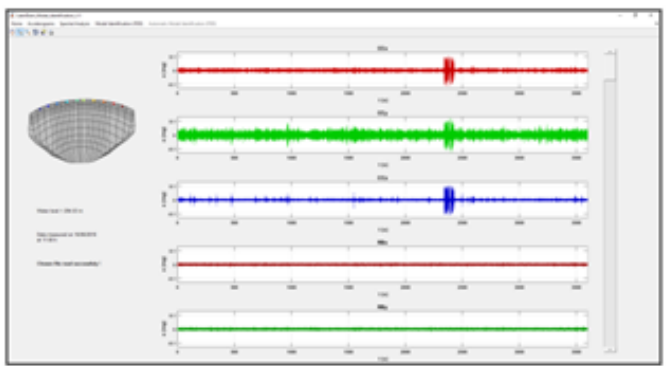

Vibrations induced by seismic events are automatically distinguished from vibrations induced by operation of gates for discharges or variations of power groups

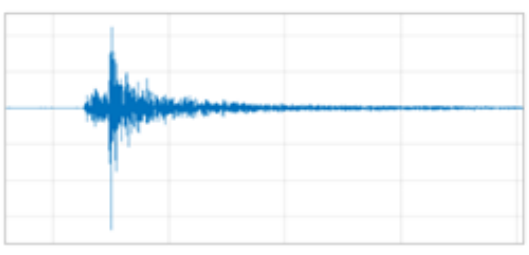

\section{SOFTWARE FOR DYNAMIC ANALYSIS USING 3DFE MODELS}

DamDySSA4.O. Dynamic analysis of concrete dams

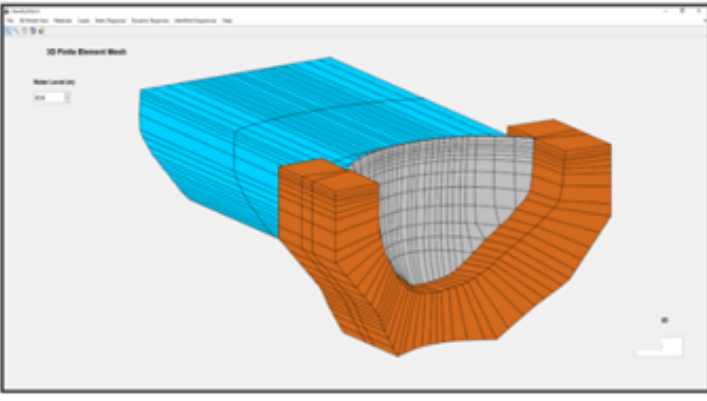

Module 2: Linear seismic analysis

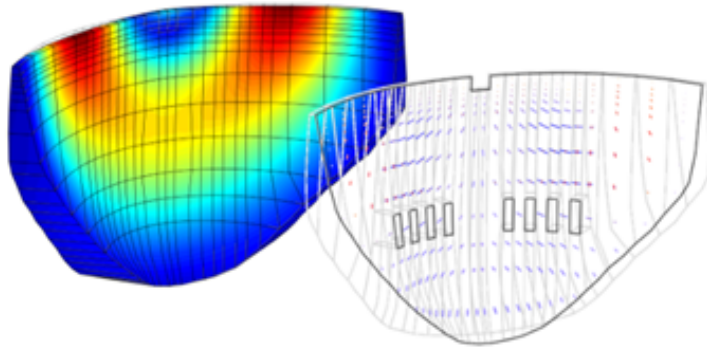

Module 1: Modal Analysis

State Space Approach (Generalized damping, complex modes)
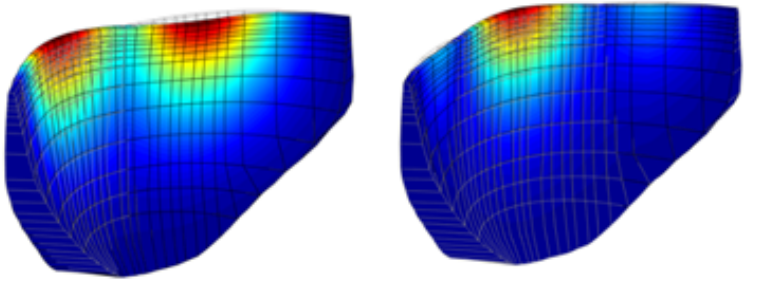

Module 3: Non-linear seismic analysis

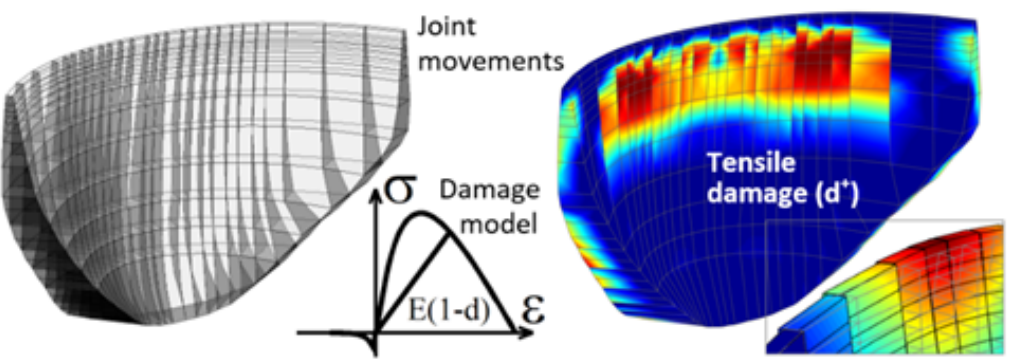

\section{Figure 3}

Software for monitoring data analysis and software for FE analysis 
a) Frequency domain decomposition (FDD) method\& Singular Value Decomposition (SVD)

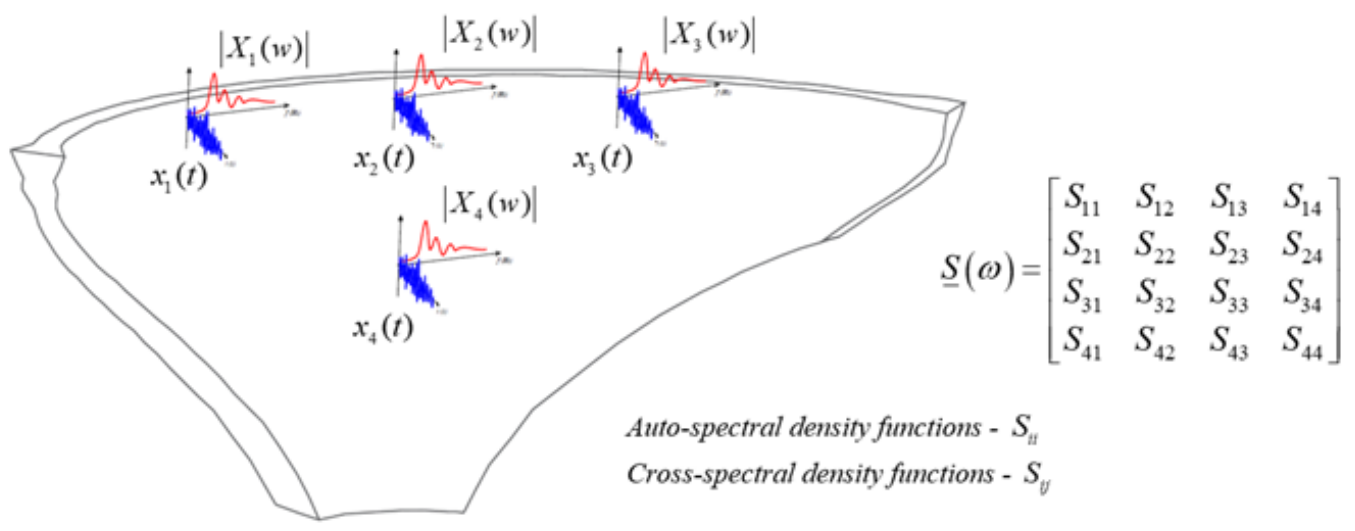

$$
\begin{array}{cc}
\text { Spectral density matrix } & \begin{array}{c}
\text { Singular values (S) and } \\
\text { singular vectors (U) }
\end{array} \\
S_{i j}\left(\omega_{k}\right)=\frac{1}{n_{s}} \sum_{k=1}^{n_{s}}\left[\frac{\bar{X}_{i}\left(\omega_{k}\right) \cdot X_{j}\left(\omega_{k}\right)}{T_{s} \cdot \sum_{p}^{N_{s}}\left|w_{s, p}\right|^{2} / N_{s}}\right]_{k} & \underline{S}\left(\omega_{k}\right)=\underline{\mathrm{U}}_{k} \cdot \underline{\mathrm{S}}\left(\omega_{k}\right) \cdot \underline{\mathrm{U}}_{k}^{\mathrm{H}}
\end{array}
$$

b) Automatic peak selection (singular value spectra) and definition of mode shapes (singular vector)

First singular value spectrum

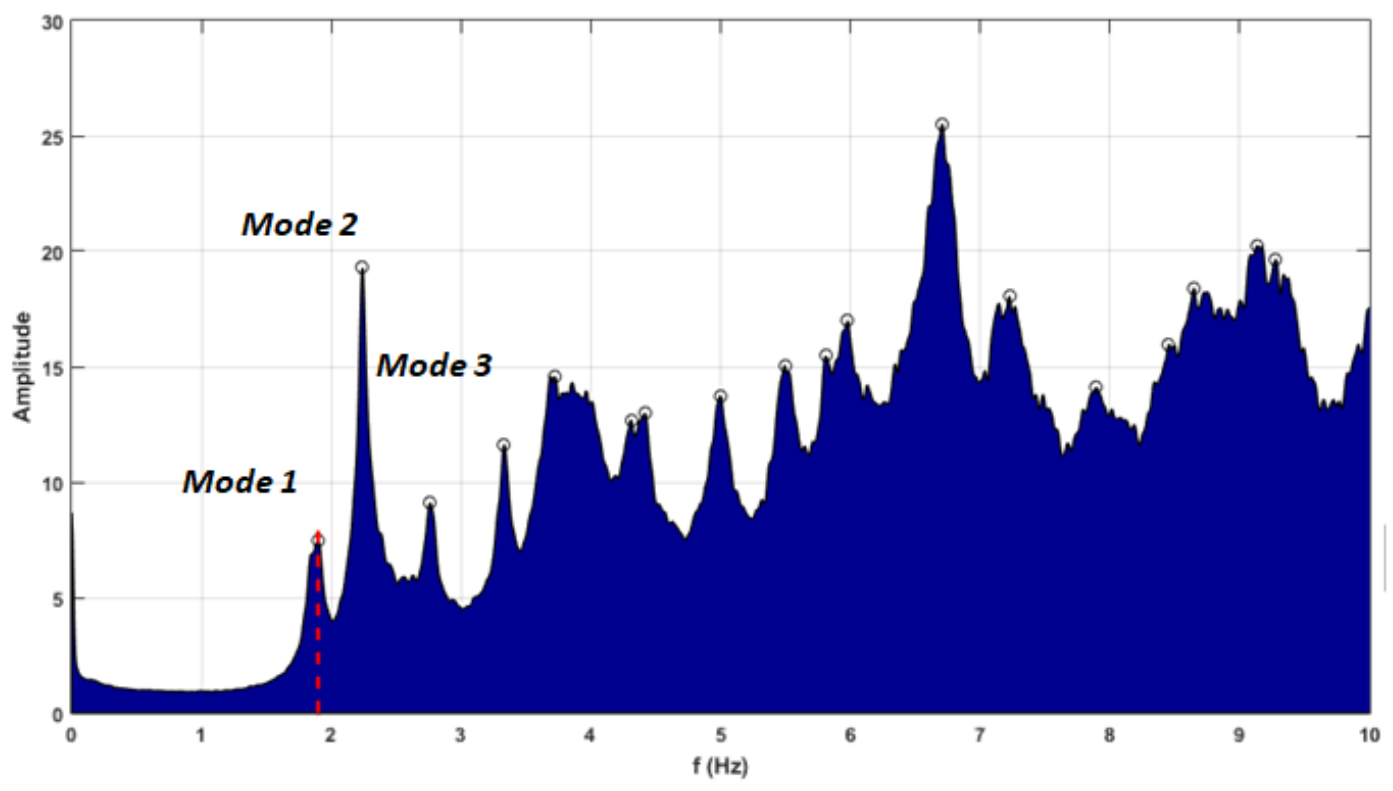

First singular vector

$$
\left[\begin{array}{c}
a_{1}+i b_{1} \\
\vdots \\
a_{n}+i b_{n}
\end{array}\right]
$$

Modal displacement ( $t)$

$y_{n}(t)=Y_{n} \cdot \cos \left(\omega_{1}-\theta_{n}\right)$

Mode shape

\section{Figure 4}

DamModalID: a) Frequency domain decomposition method and singular value decomposition: main mathematical formulas; and b) Automatic selection of spectral peaks from the first singular value spectrum, and definition of first mode shape from the corresponding singular vector. 
a) Coupled formulation in displacements ( $u$ ) and pressures ( $p$ )

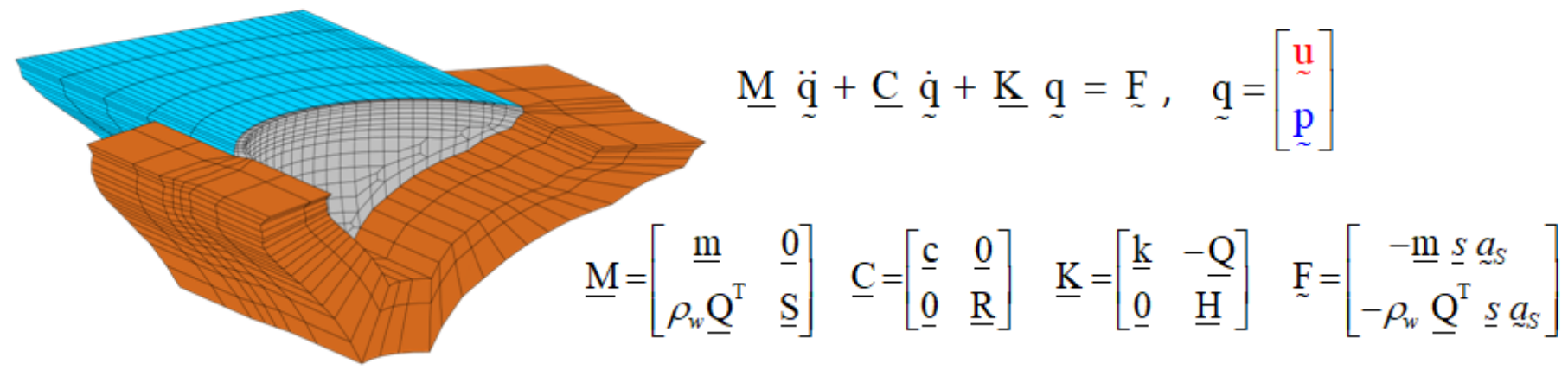

b) Modal Analysis. State space approach (complex eigenvalues and eigenvectors)

$$
\underset{\sim}{\dot{\mathrm{x}}}=\underline{\mathrm{A}} \underset{\sim}{\mathrm{x}}+\underline{\mathrm{P}}, \underset{\sim}{\mathrm{x}}=\left[\begin{array}{c}
\mathrm{q} \\
\underset{\sim}{\mathrm{q}}
\end{array}\right]
$$
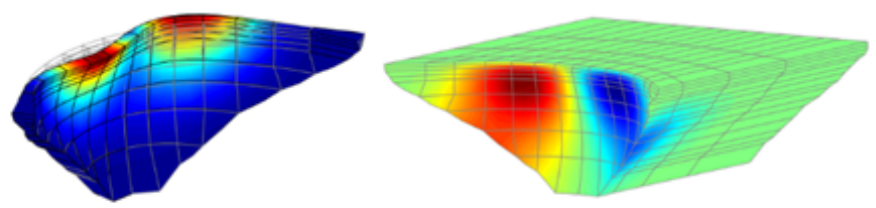

$$
\underline{\mathrm{A}}=\left[\begin{array}{cc}
\underline{0} & \underline{\mathrm{I}} \\
-\underline{\mathrm{M}}^{-1} \underline{\mathrm{K}} & -\underline{\mathrm{M}}^{-1} \underline{\mathrm{C}}
\end{array}\right] \quad \underline{\mathrm{P}}=\left[\begin{array}{c}
\underset{\sim}{\mathrm{N}} \\
\underline{\mathrm{M}}^{-1} \underset{\sim}{\mathrm{F}}
\end{array}\right]
$$
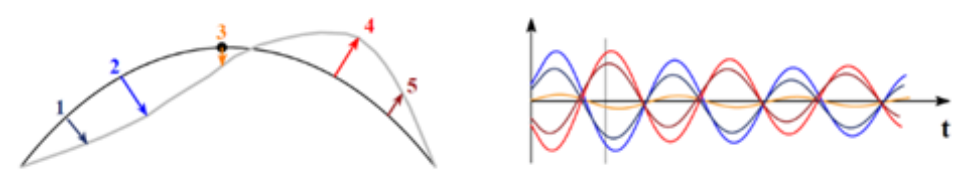

c) Linear seismic response. Coupled time-stepping formulation (Newmark method)

$$
\begin{aligned}
& \underline{\mathrm{K}^{*}} \cdot{\underset{\sim}{\mathrm{t}}+\Delta t}_{\sim}={\underset{\mathrm{P}}{t+\Delta t}}^{*}
\end{aligned}
$$

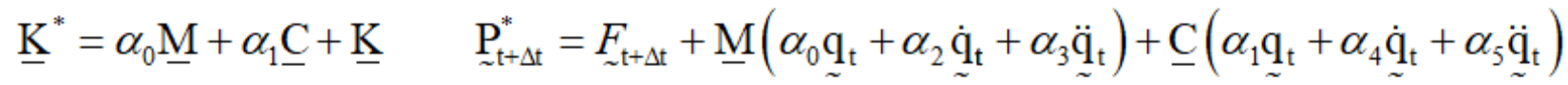

d) Non-Linear seismic response: time-stepping and stress-transfer method. Constitutive models to simulate joint movements and concrete damage $\left(d^{+}, d^{-}\right)$

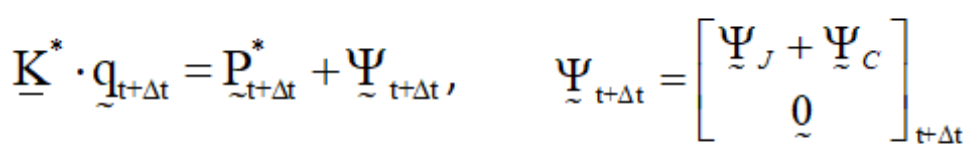
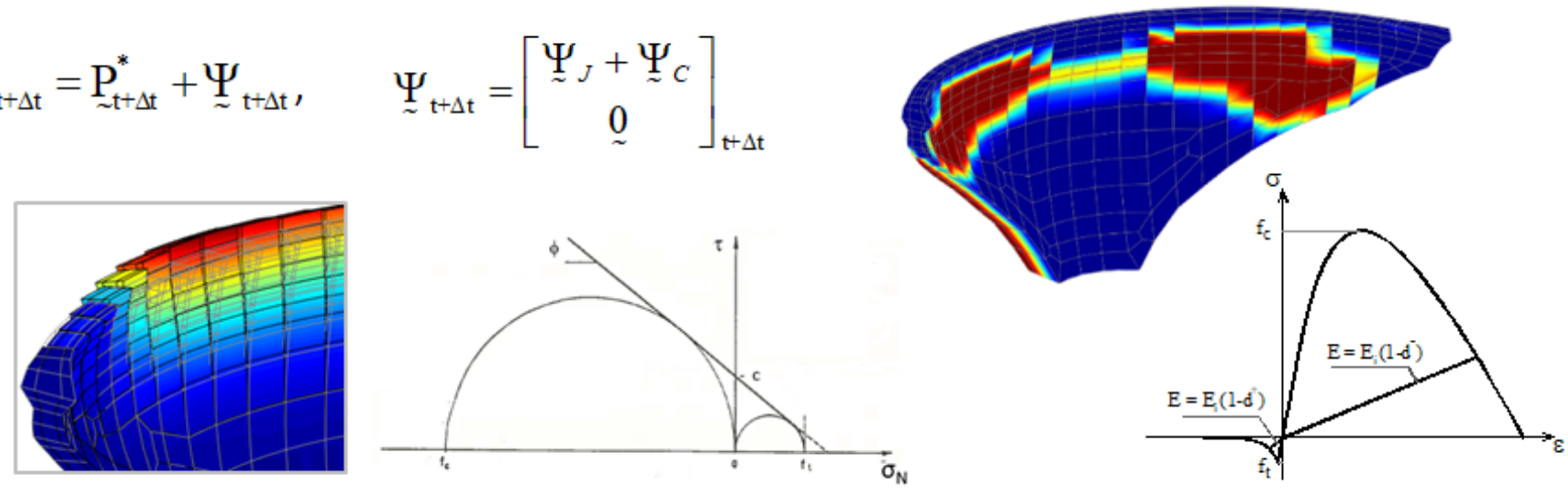

Figure 5

DamDySSA: a) Coupled formulation in displacements and pressures; b) State-space approach for complex modal analysis; c) Time-stepping procedure for linear seismic analysis; d) Formulation for nonlinear seismic analysis. 

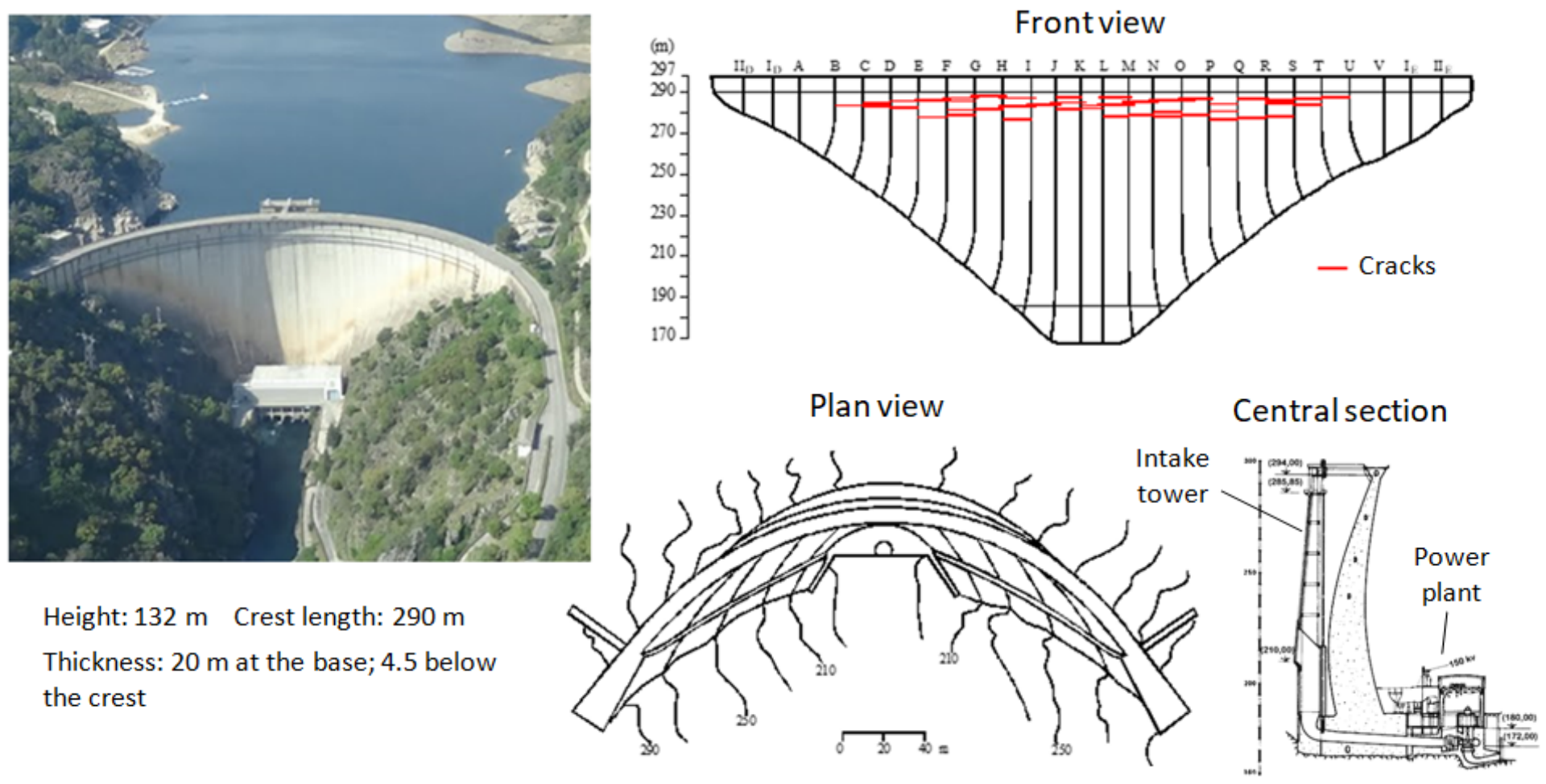

Figure 6

Cabril dam. Aerial view and technical drawings.

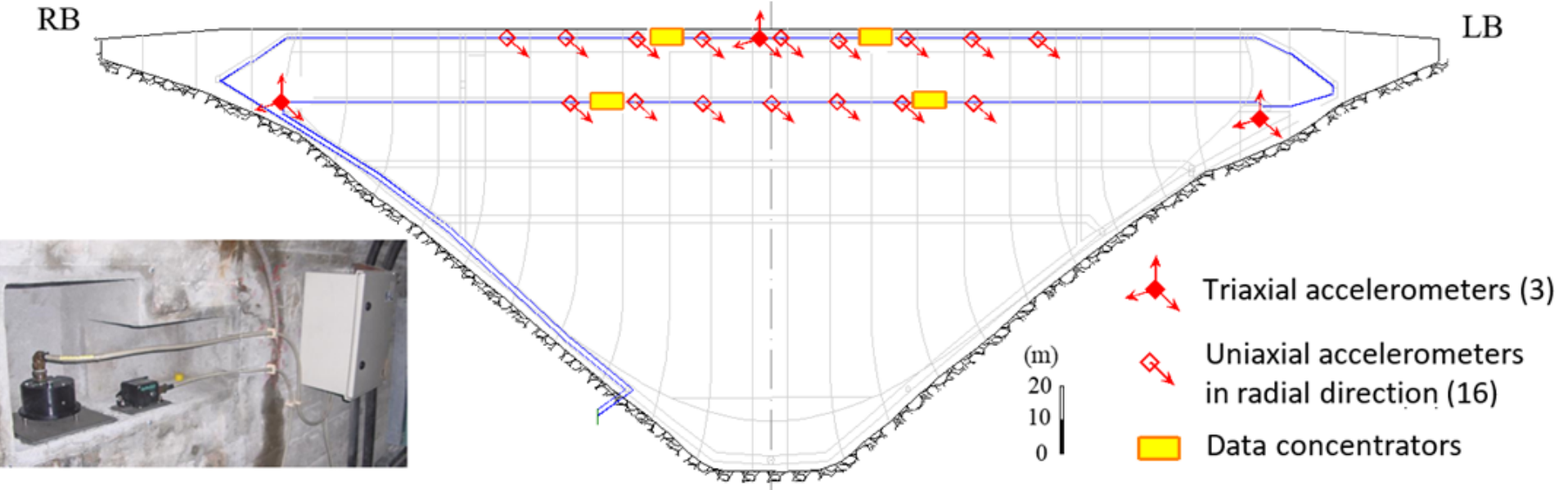

Figure 7

Seismic and Structural Health Monitoring system installed inCabril dam in 2008. 


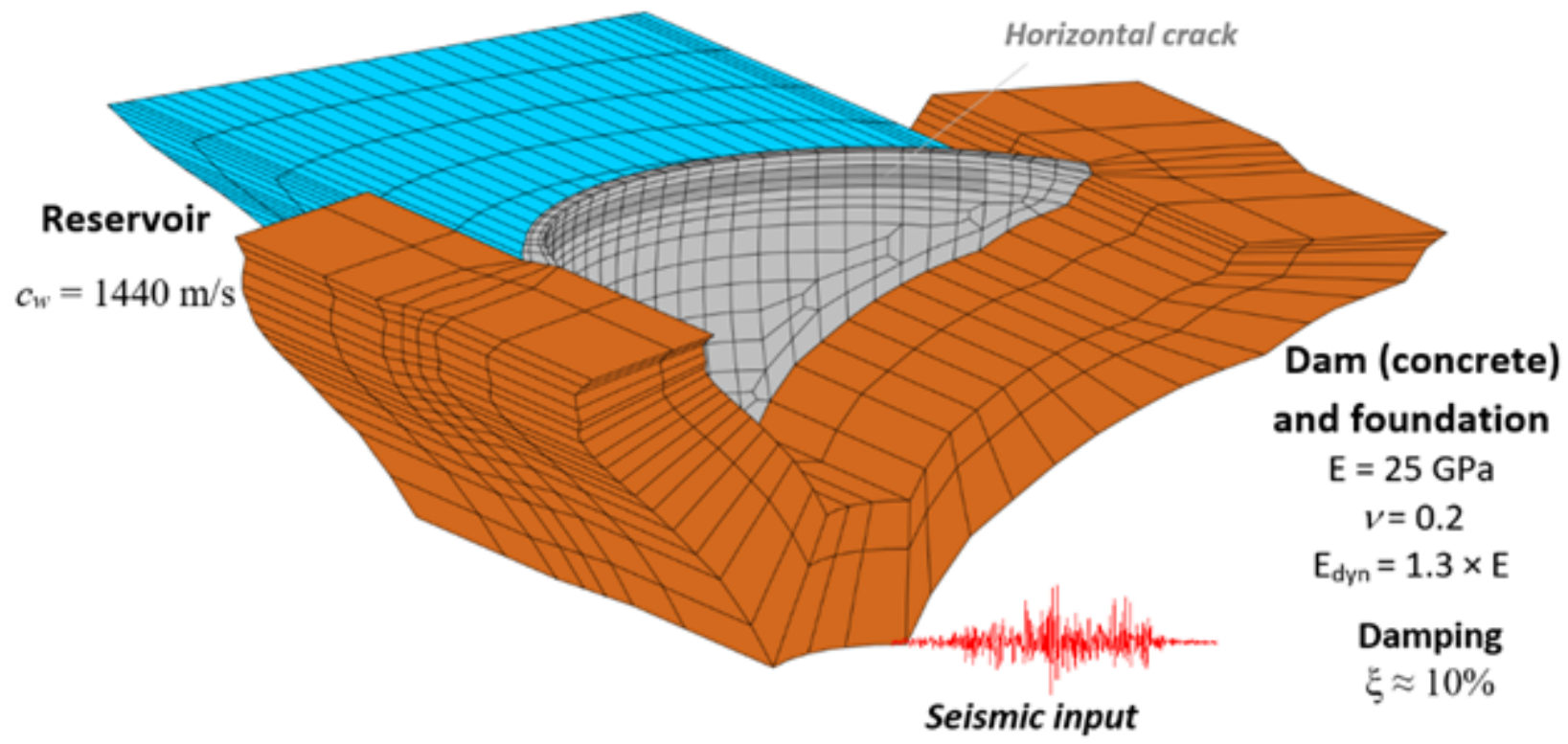

Non-linear behavior
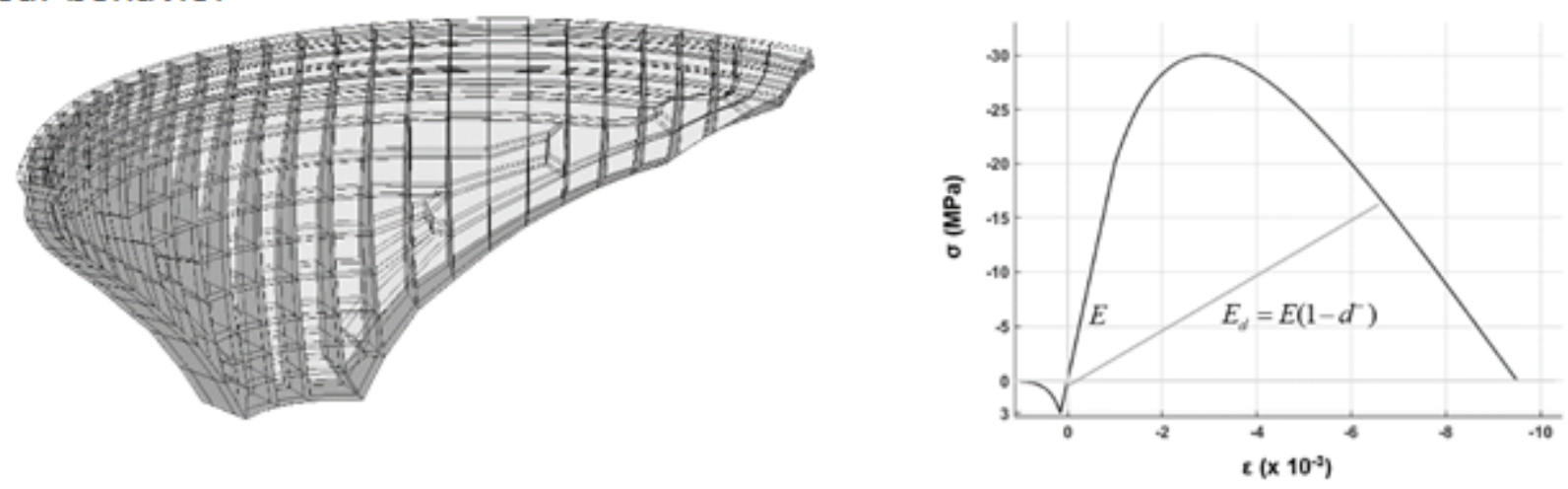

Figure 8

Cabril dam: 3DFE model of the dam-reservoir-foundation system. Material properties, joint elements, and constitutive damage law for concrete. 

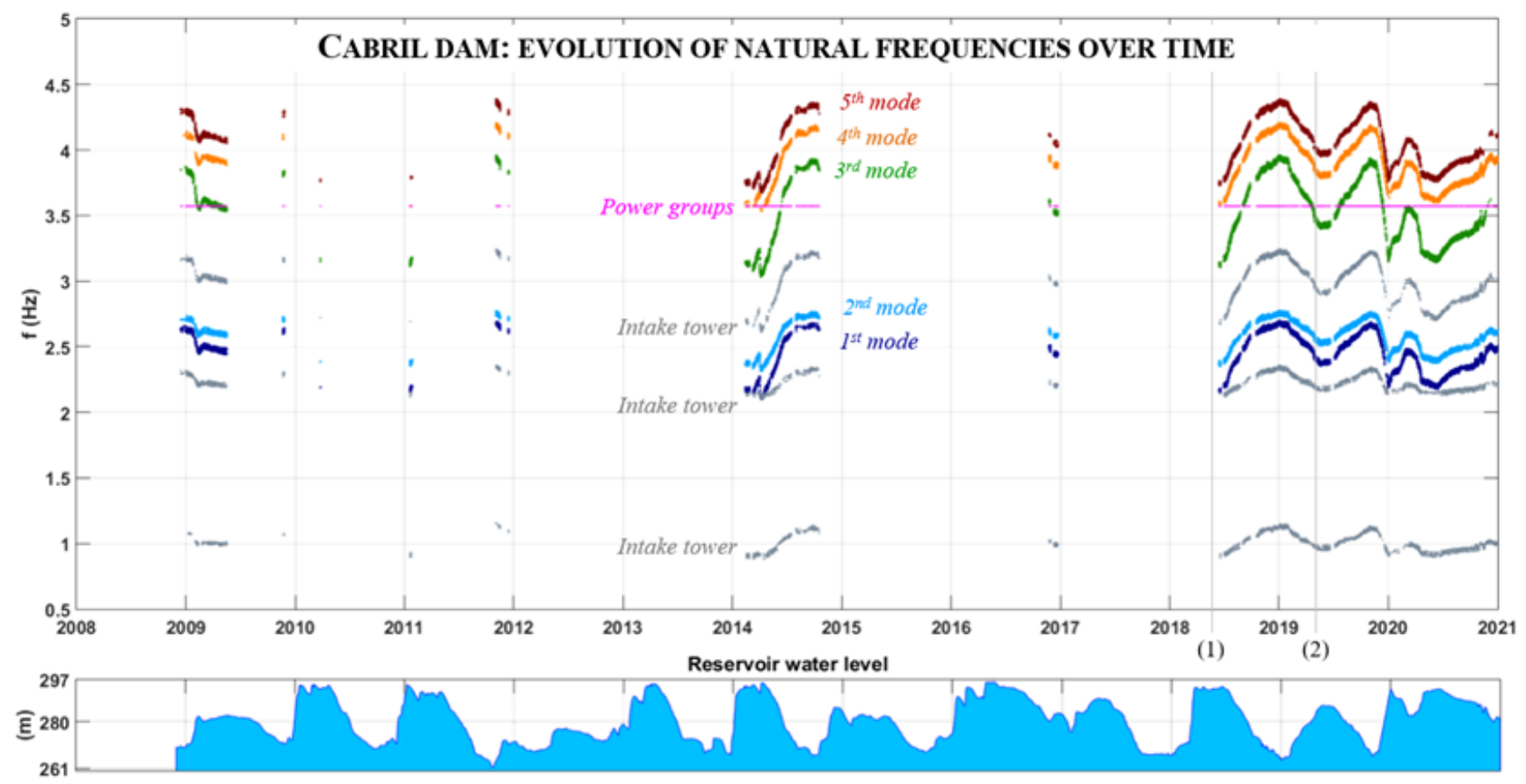

Modal identification results: measured signals on June 16, 2018, 5 to 6 p.m., water level at el. $294 \mathrm{~m}$ (1)
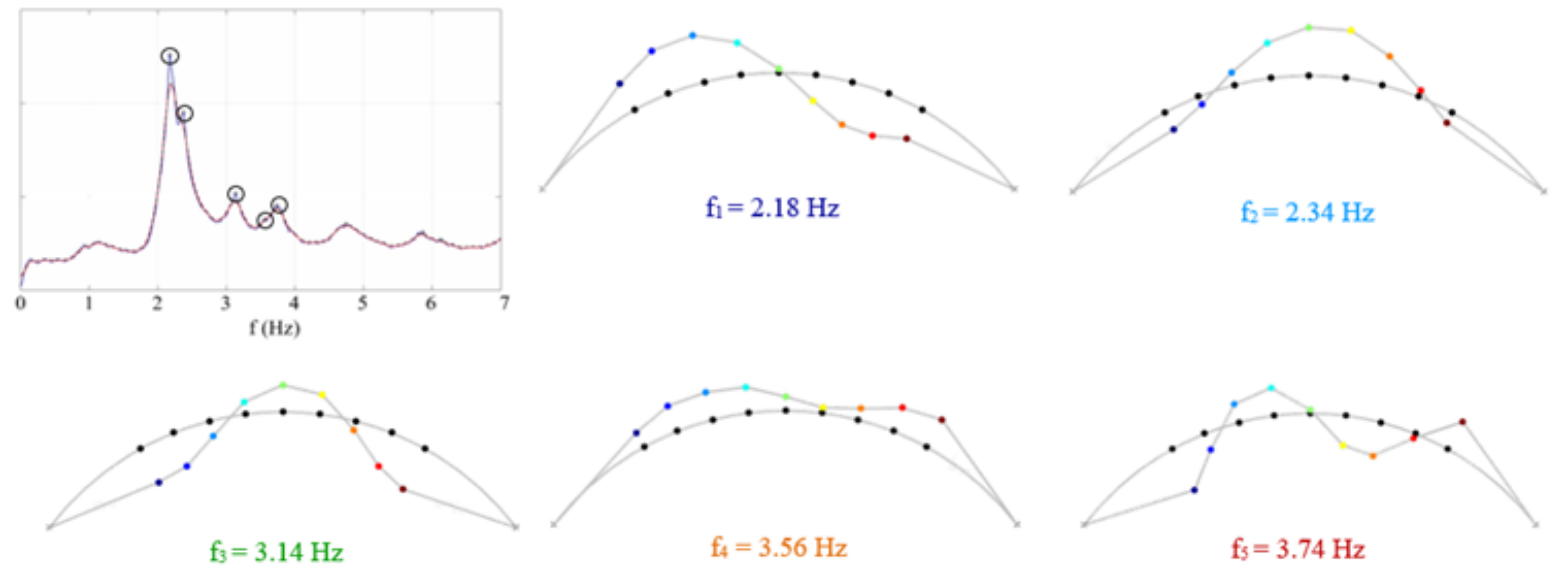

Modal identification: accelerations measured on May 4, 2019, 4 to 5 a.m., water level at el. $285.1 \mathrm{~m}$ (2)
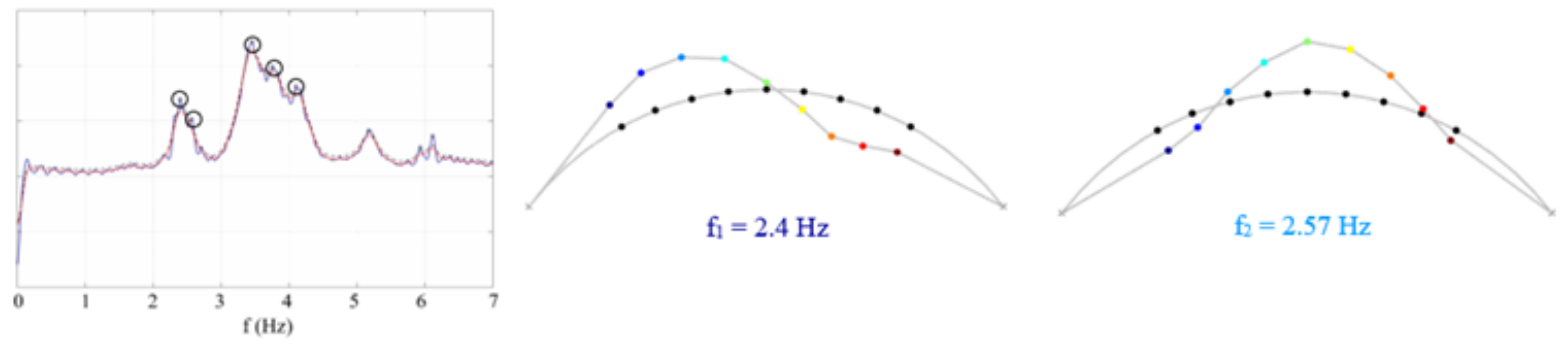

\section{Figure 9}

Results from continuous dynamic monitoring of Cabril dam: evolution of identified natural frequencies over time (2008 to 2020). Singular value spectra and estimated frequencies and mode shapes for specific times/dates. 

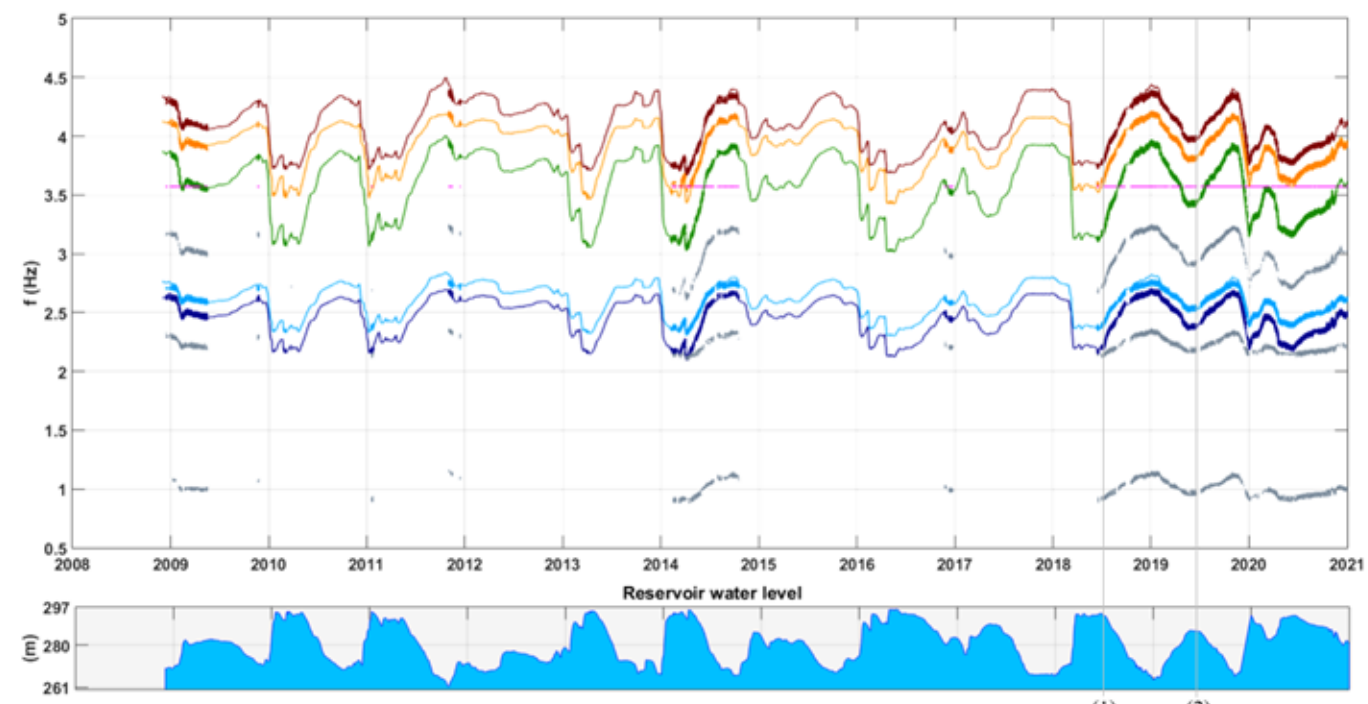

(1) (2)

Modal analysis results considering the reservoir water level at el. $293.5 \mathrm{~m}$ (1)
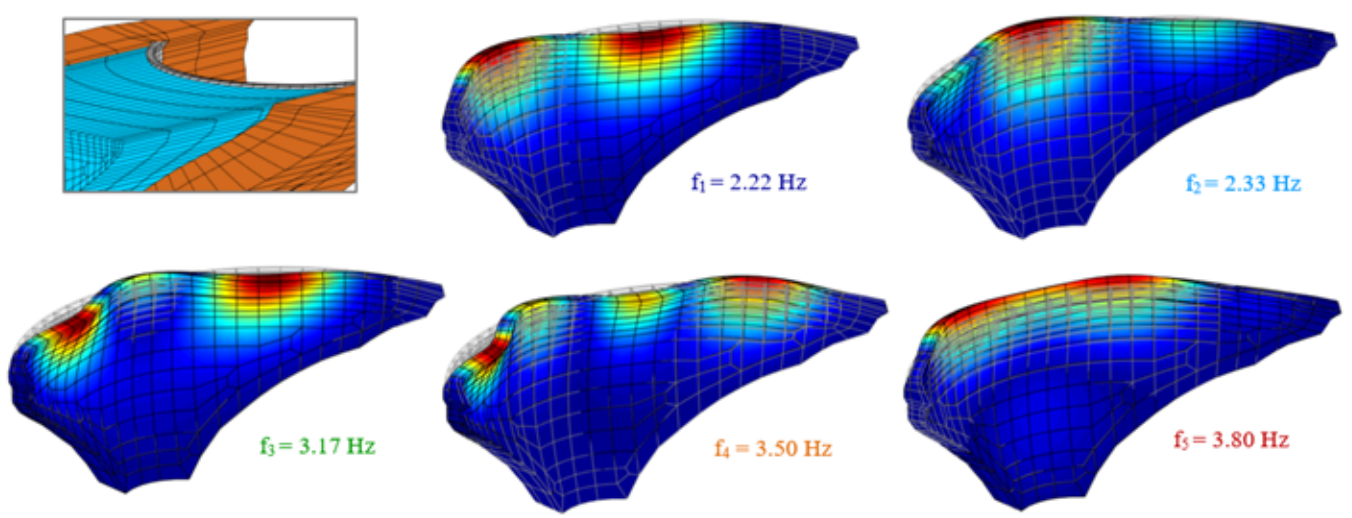

Modal analysis results considering the reservoir water level at el. $285 \mathrm{~m}$ (2)
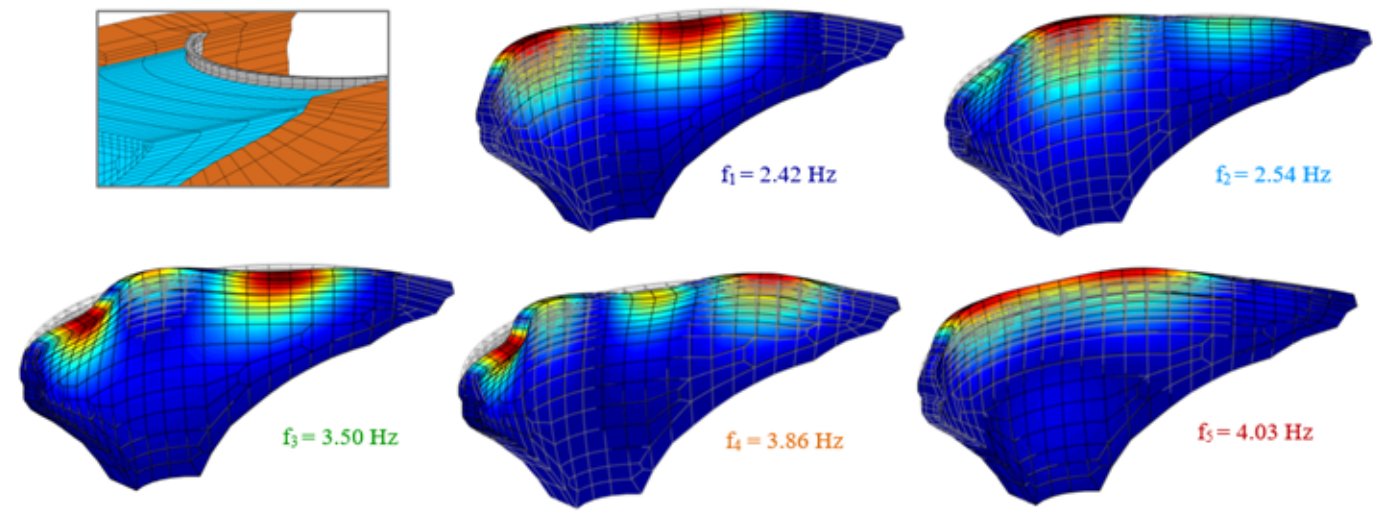

Figure 10

Comparison between identified natural frequencies over time and computed frequencies for Cabril dam. Finite element modal analysis: frequencies and mode shapes for two reservoir water levels. 


\section{MODE 1 (ANTISYMMETRIC)}

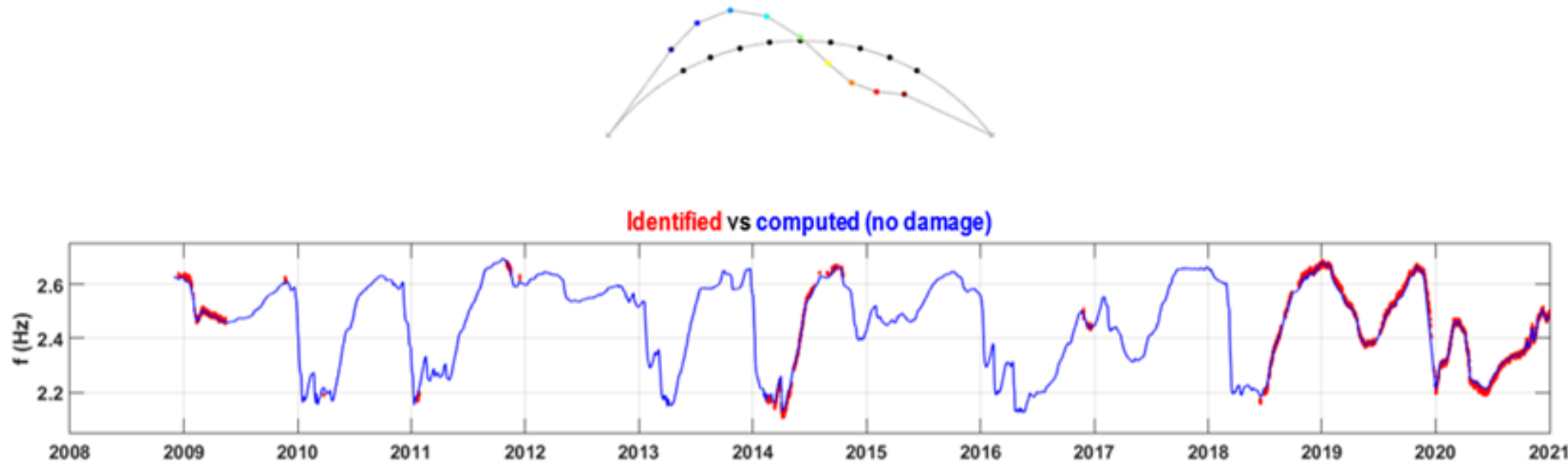

Identified vs computed (evolutive damage: 0 to $5 \%$ )
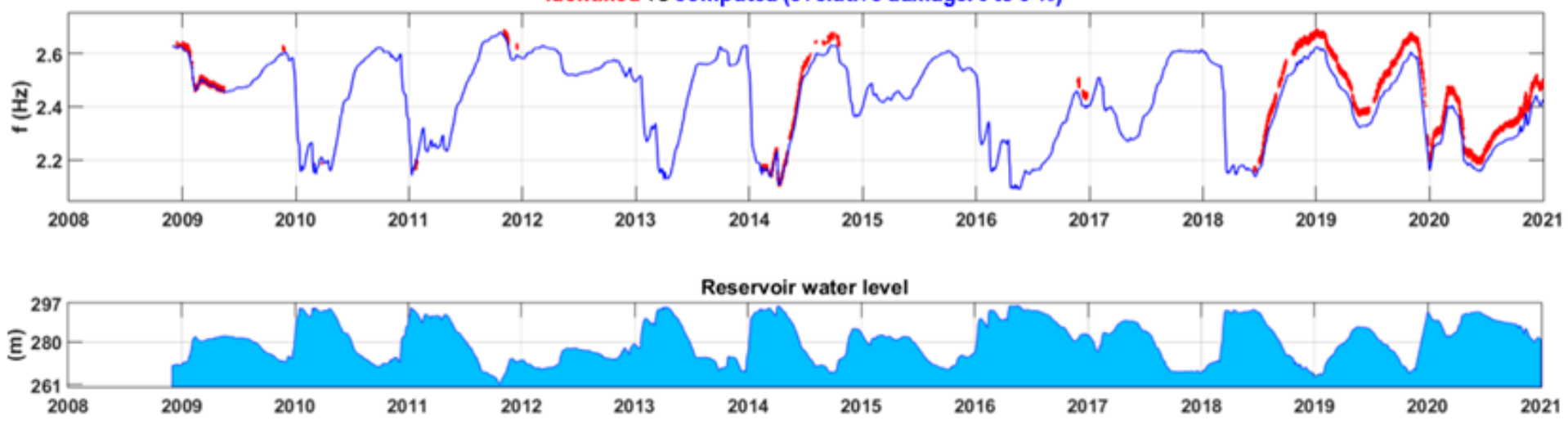

\section{Figure 11}

Vibration-based analysis for damage detection. Evolution of the identified natural frequency of the first mode over time (2008-2020 and comparison with results from numerical simulations using a linear refence model and a test model with evolutive damage (0 to $5 \%$ ).

\section{Figure 12}

Seismic response of Cabril dam: seismic event (4.6M) on September 4, 2018. Comparison between measured and computed accelerations - upper gallery, central section. Note: The designations employed and the presentation of the material on this map do not imply the expression of any opinion whatsoever on the part of Research Square concerning the legal status of any country, territory, city or area or of its authorities, or concerning the delimitation of its frontiers or boundaries. This map has been provided by the authors. 


\section{Load combination: SW + HP297 + SEISMICL}

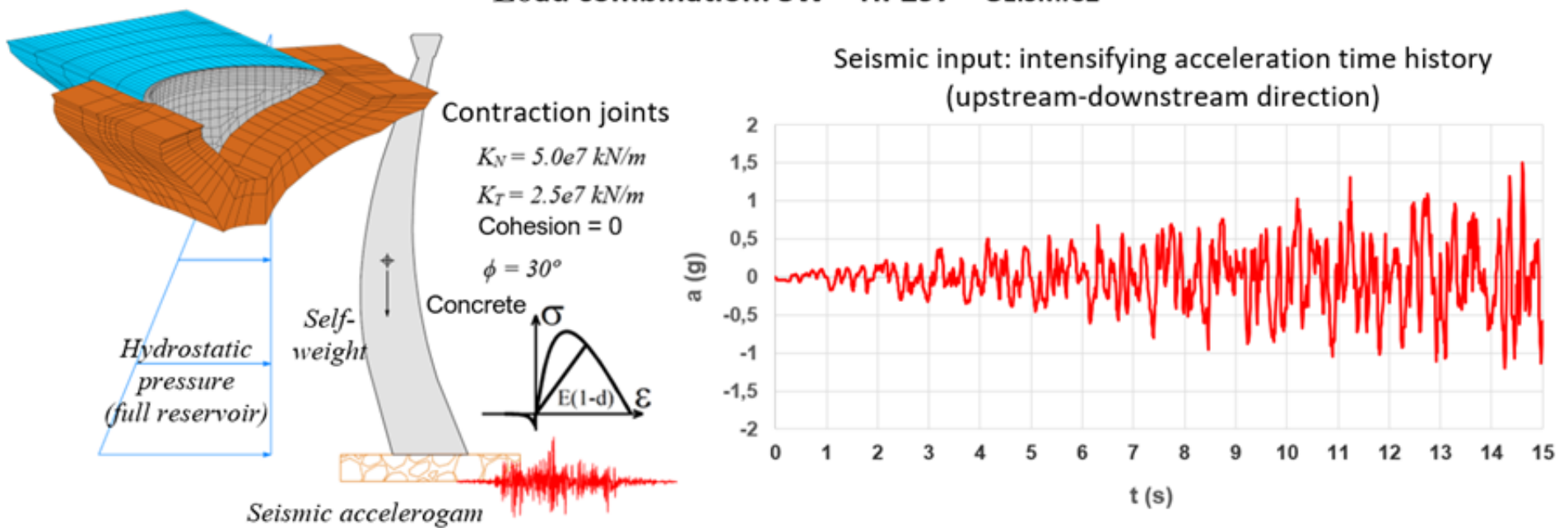

\section{Figure 13}

3DFE model of the dam-reservoir-foundation system used for non-linear seismic analysis of Cabrildam. Joints' properties, concrete constitutive law, load combination, and intensifying seismic input used for Endurance Time Analysis (ETA).

(a) Tensile damage
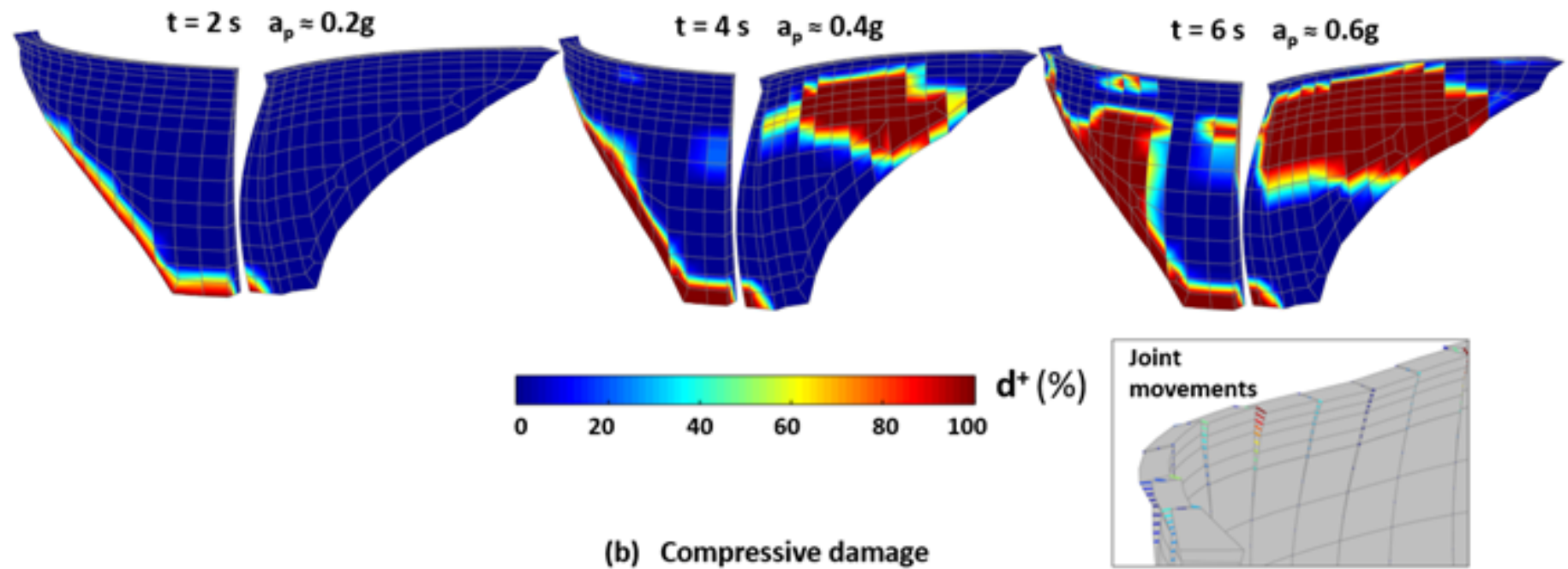

(b) Compressive damage
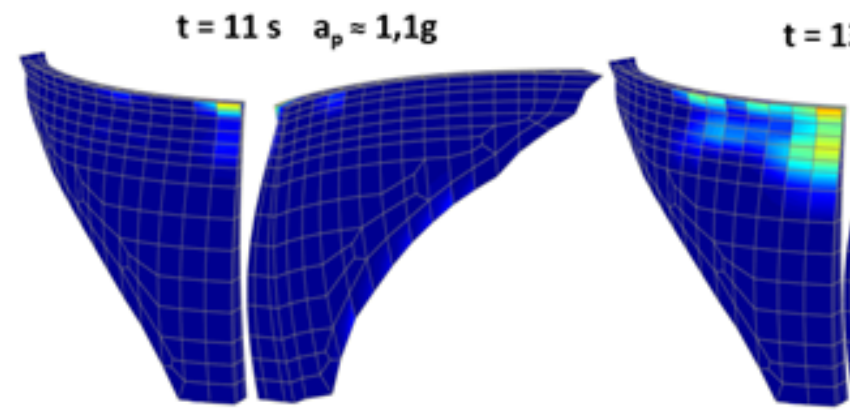

$t=13 \mathrm{~s} \quad a_{\mathrm{p}} \approx 1.3 \mathrm{~g}$
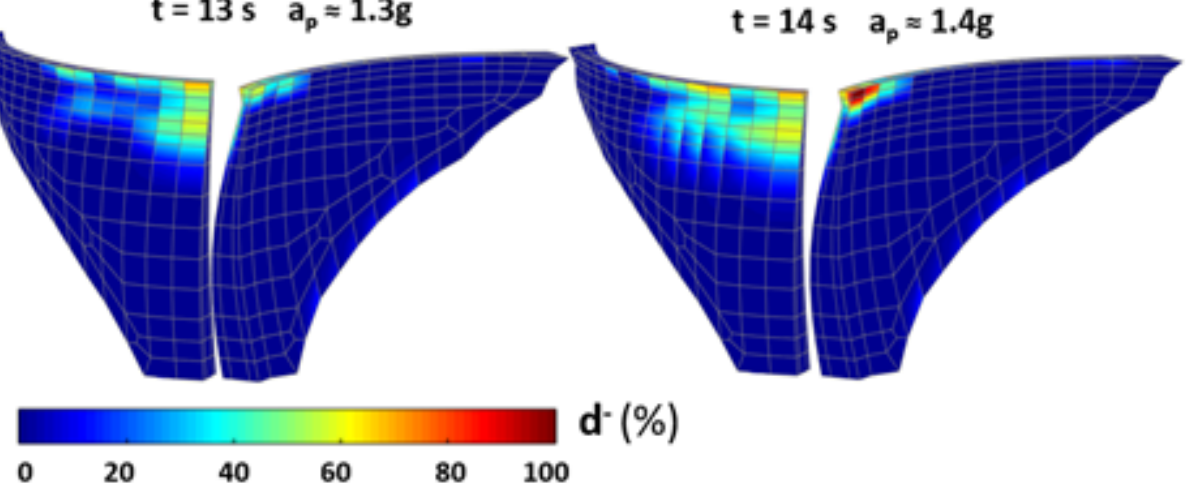

Figure 14 
Non-linear seismic behavior of Cabril dam. Performance for increasingETA excitation levels: evolution of tensile (a) and compressive damage distributions (b).
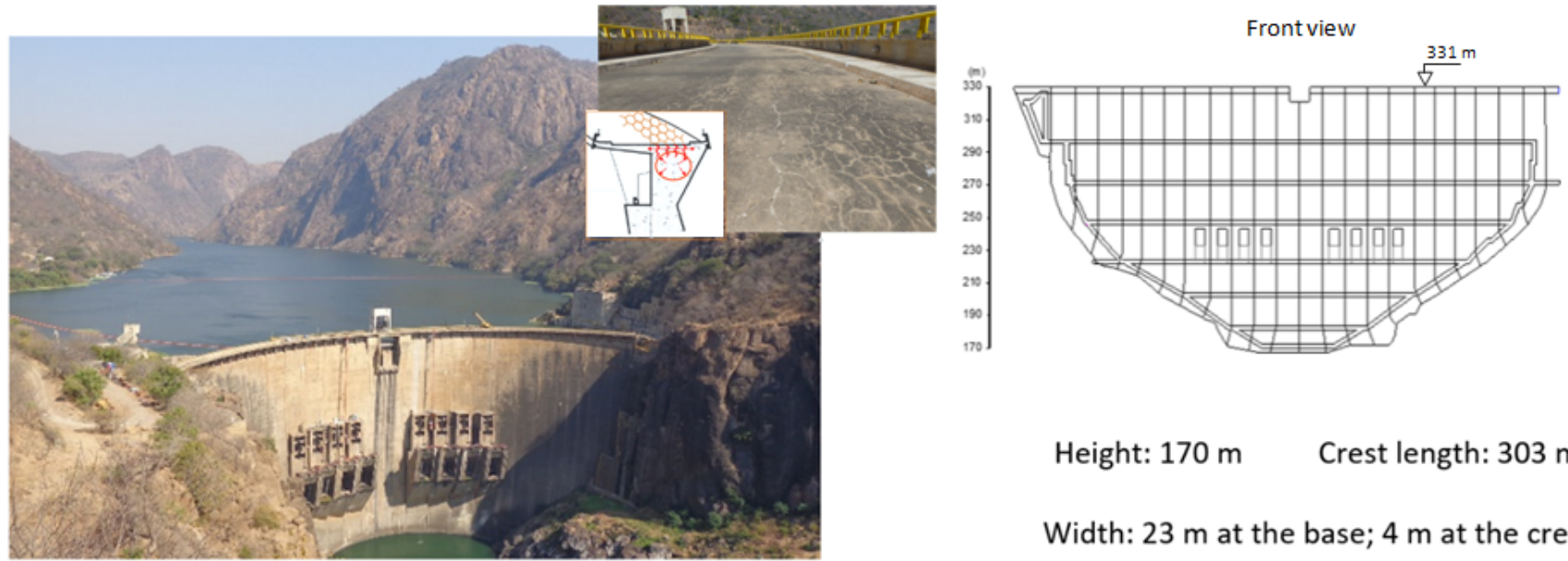

Central section

\section{Figure 15}

Cahora Bassa dam.Downstream view, crest cracking view, and technical drawings.

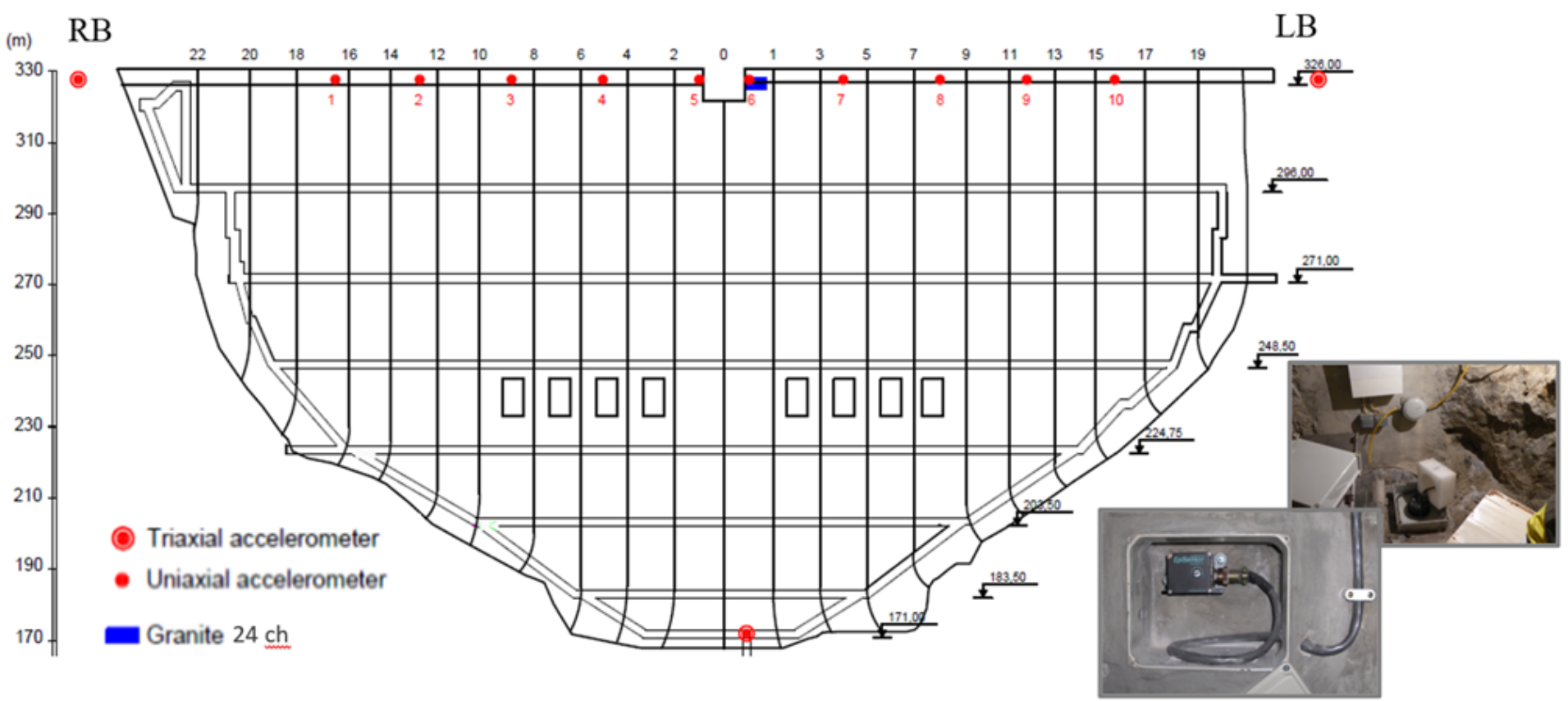

Figure 16

Seismic and Structural Health Monitoring system installed in Cahora Bassa dam in 2010 


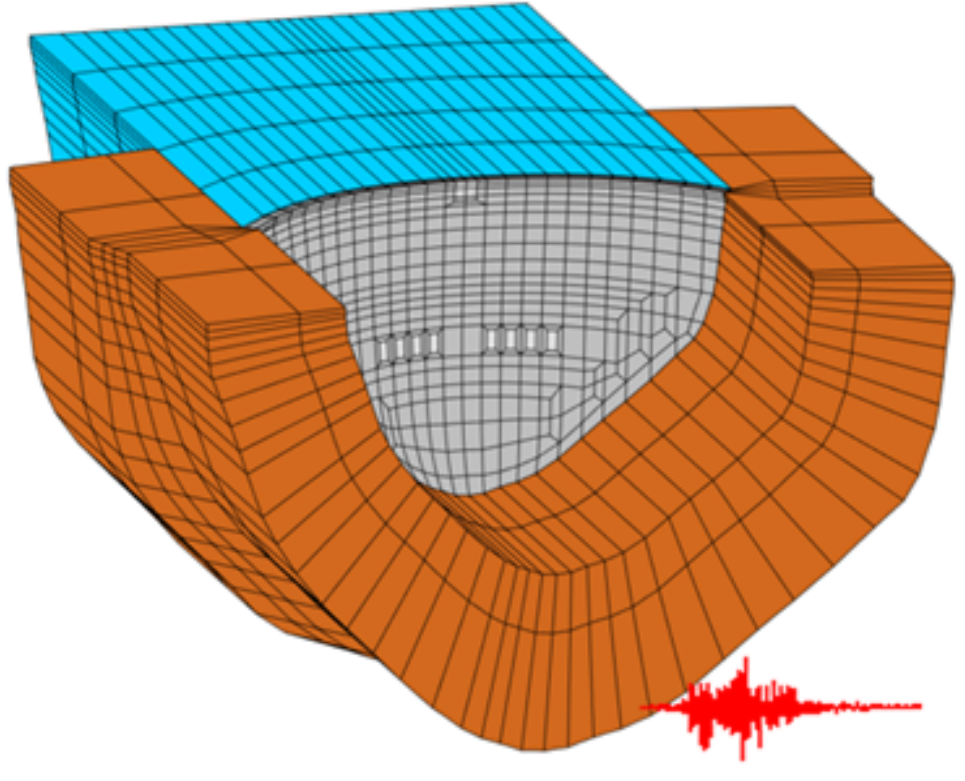

\section{Dam (concrete)}

$\mathrm{E}=40 \mathrm{GPa} ; \quad v=0.2 ; \quad \gamma=24 \mathrm{kN} / \mathrm{m}^{3}$

\section{Foundation (rock)}

$\mathrm{E}=40 \mathrm{GPa} ; v=0.2$

\section{Reservoir (water)}

$c w=1500 \mathrm{~m} / \mathrm{s} ; \quad \gamma=10 \mathrm{kN} / \mathrm{m}^{3}$

Damping

$\xi \approx 1 \%$
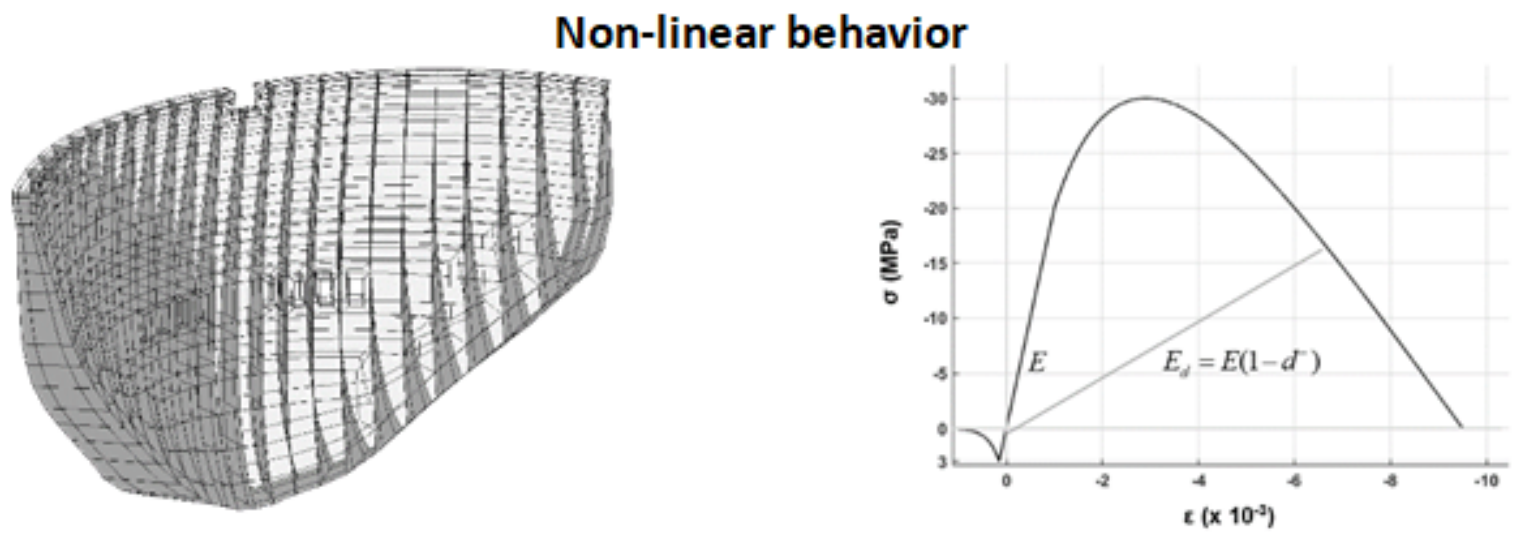

Figure 17

Cahora Bassa dam: 3DFE model of the dam-reservoir-foundation system. Material properties, joint elements, and constitutive damage law for concrete. 


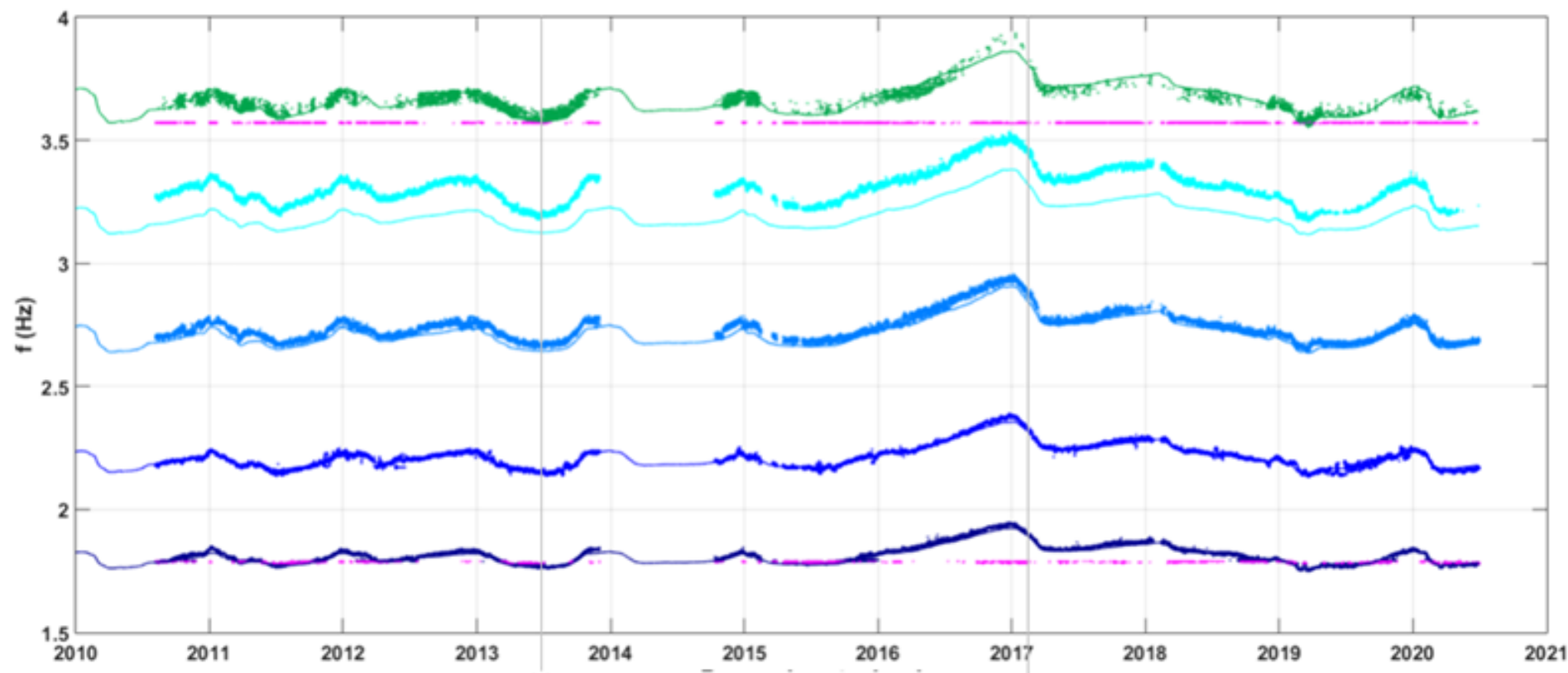

(1)

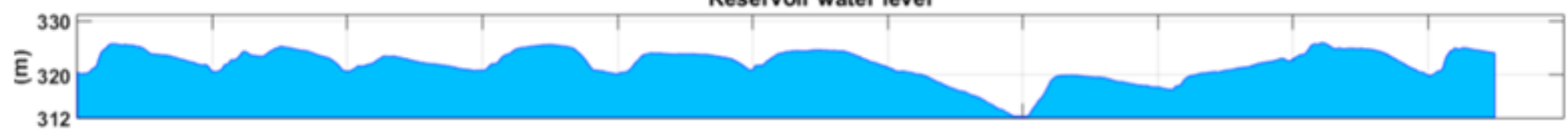

Modal analysis results considering the reservoir water level at el. $326 \mathrm{~m}$ (1)
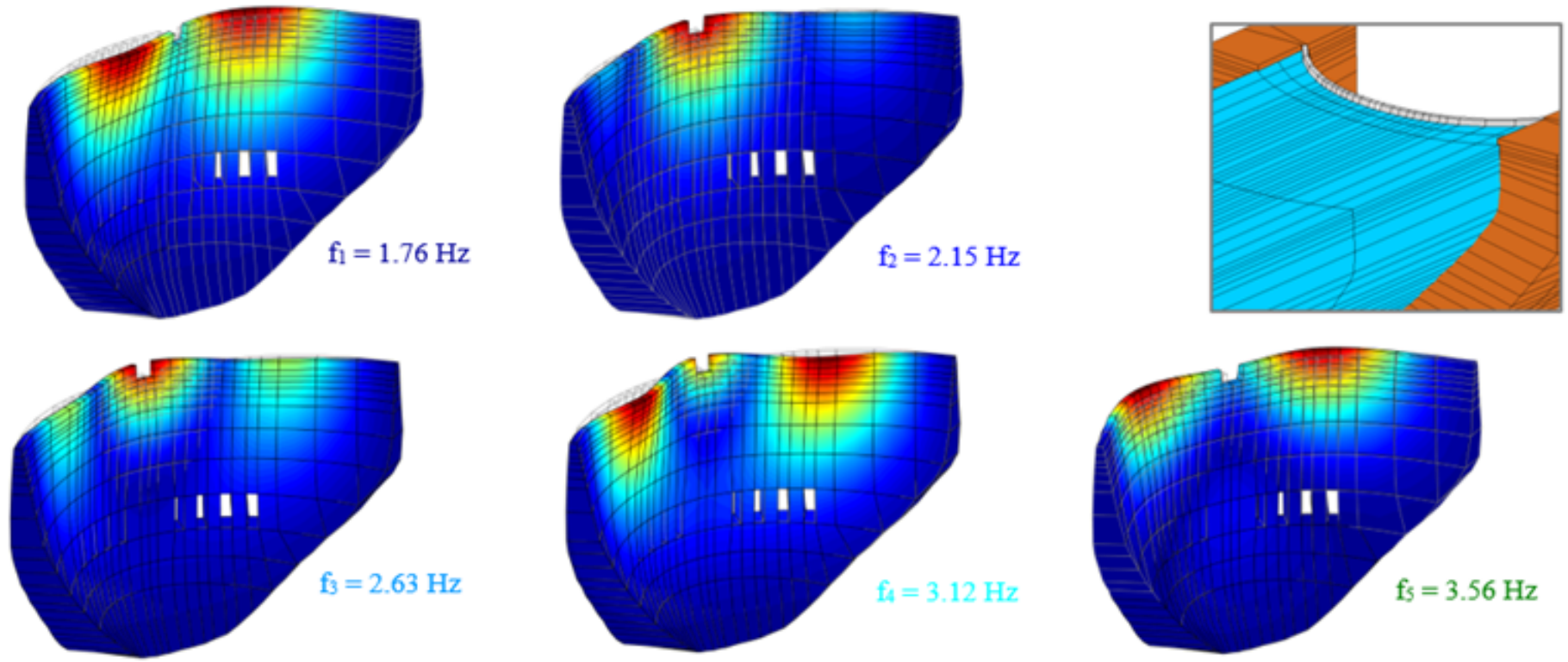

Figure 18

Results from continuous dynamic monitoring of Cahora Bassa dam: evolution of identified natural frequencies over time (2010 to 2020) and comparison with calculated natural frequencies. Numerical mode shapes. 


\section{MODE 1 (ANTISYMMETRIC)}

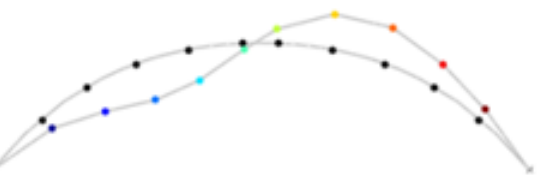

(a) Identified vs computed (no damage)

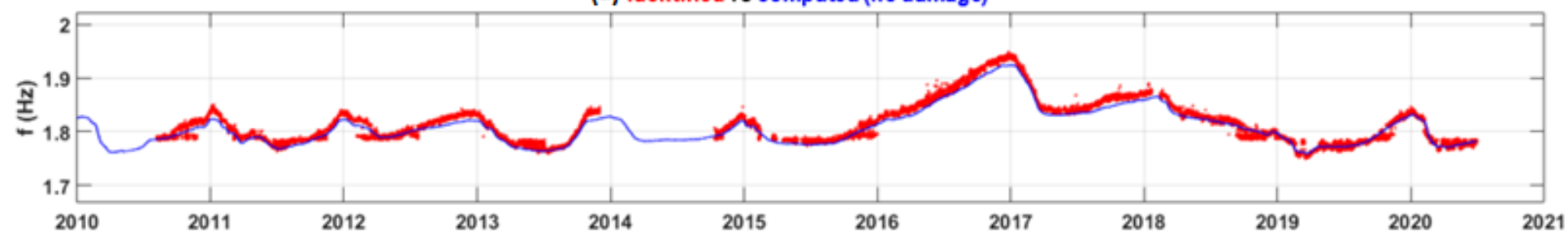

(b) Identified vs computed (evolutive damage: 0 to $5 \%$ )
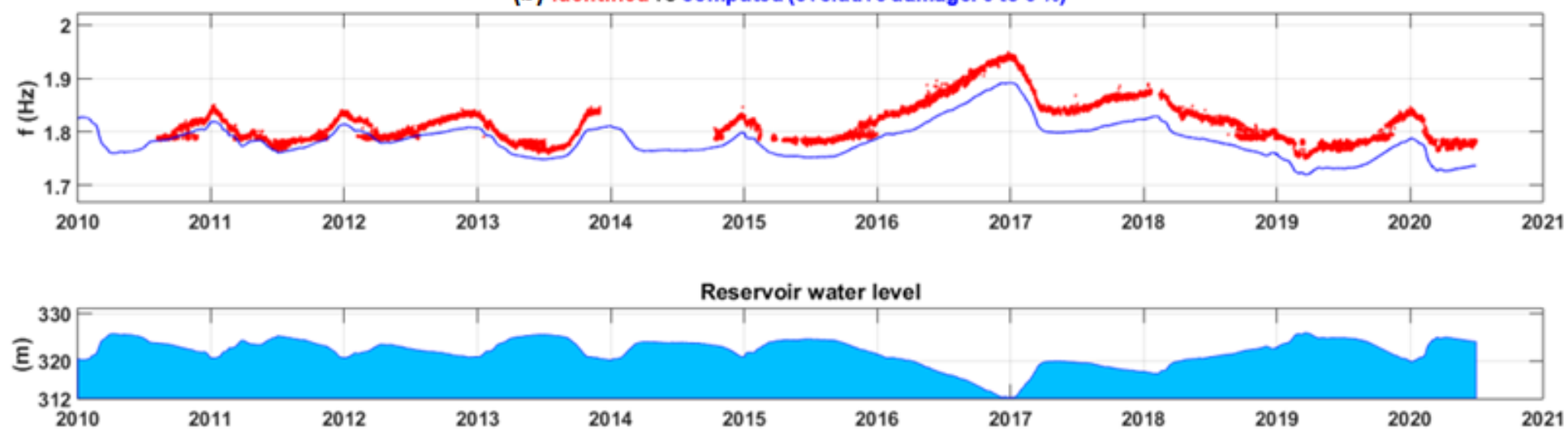

\section{Figure 19}

Vibration-based analysis for damage detection. Evolution of the identified natural frequency of the first mode over time (2010-2020) and comparison with results from numerical simulations using a linear refence model and a test model with evolutive damage (0 to $5 \%$ ).

\section{Figure 20}

Seismic response of Cahora Bassa dam: seismic event on June 21, 2017. Comparison between measured and computed accelerations - upper gallery, central section. Note: The designations employed and the presentation of the material on this map do not imply the expression of any opinion whatsoever on the part of Research Square concerning the legal status of any country, territory, city or area or of its authorities, or concerning the delimitation of its frontiers or boundaries. This map has been provided by the authors. 


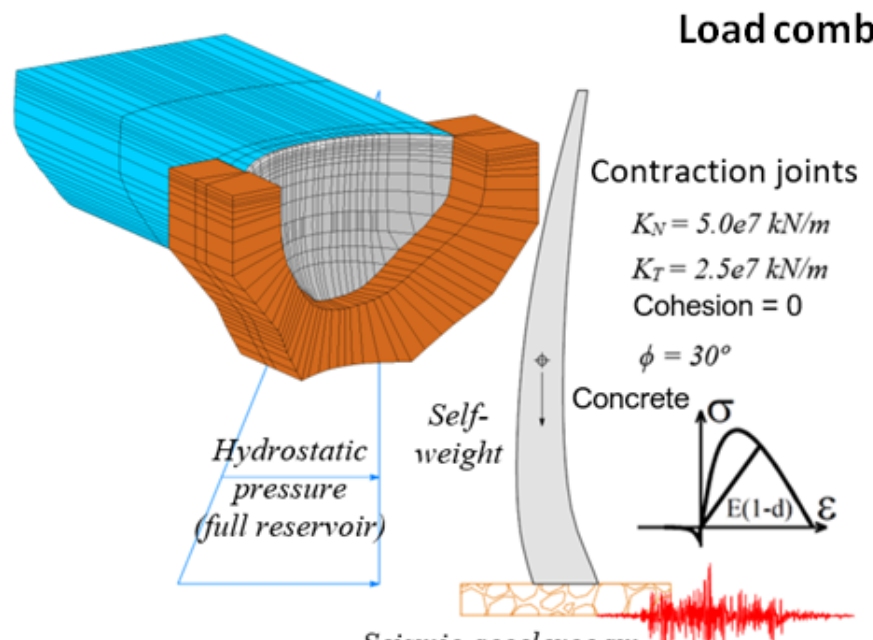

Seismic accelerogam

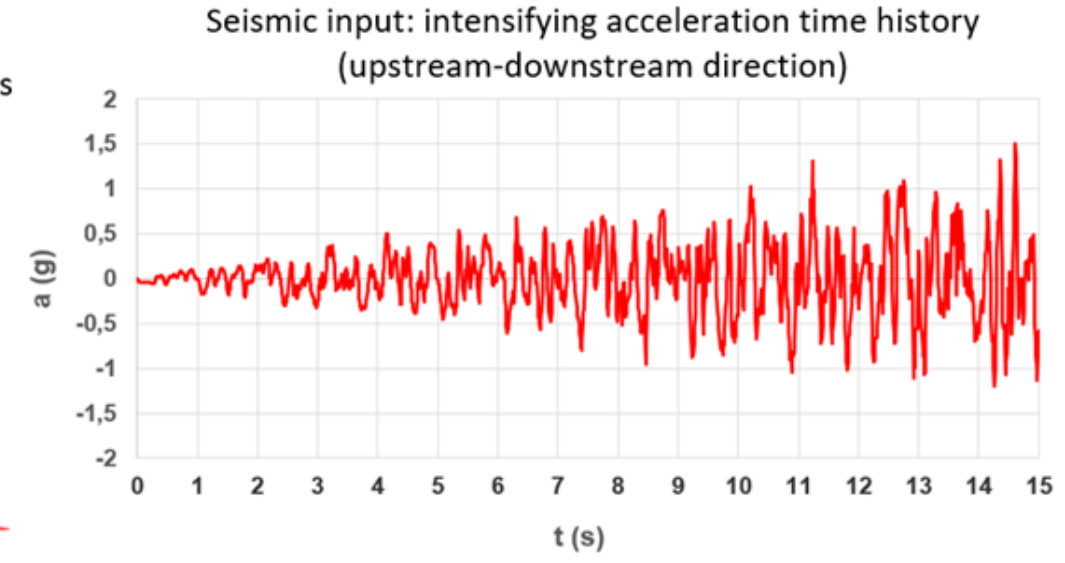

Figure 21

3DFE model of the dam-reservoir-foundation system used for non-linear seismic analysis of Cahora Bassadam. Joints' properties, concrete constitutive law, load combination, and intensifying seismic input used for Endurance Time Analysis.

(a) Tensile damage
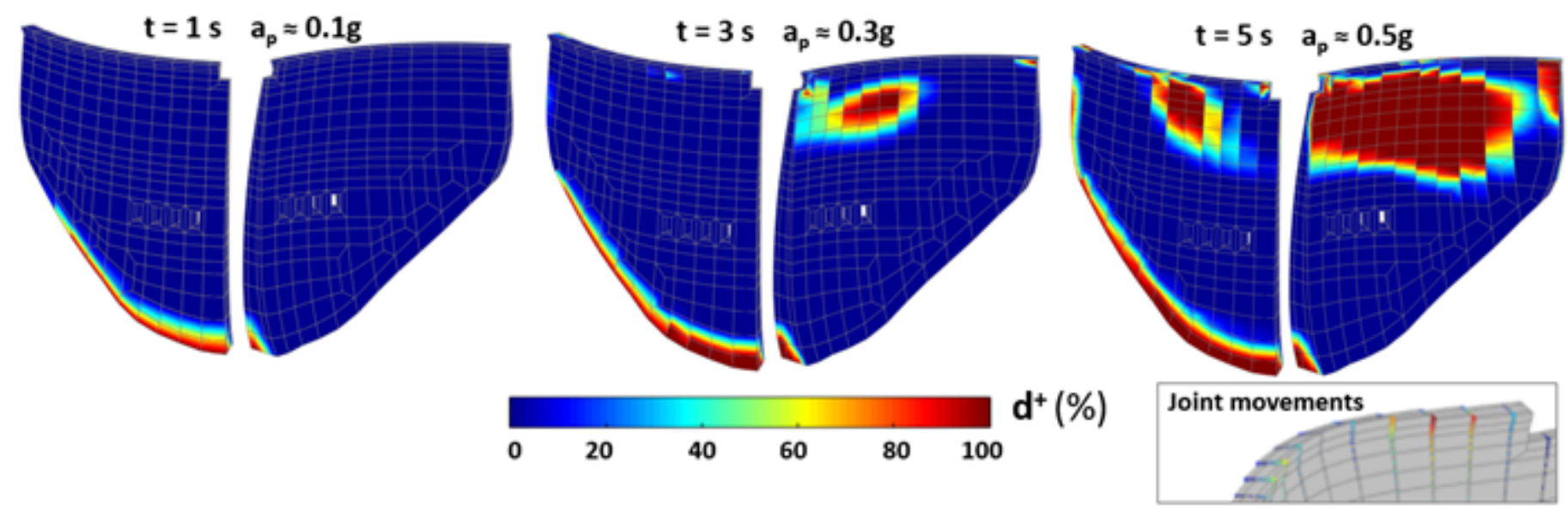

(b) Compressive damage
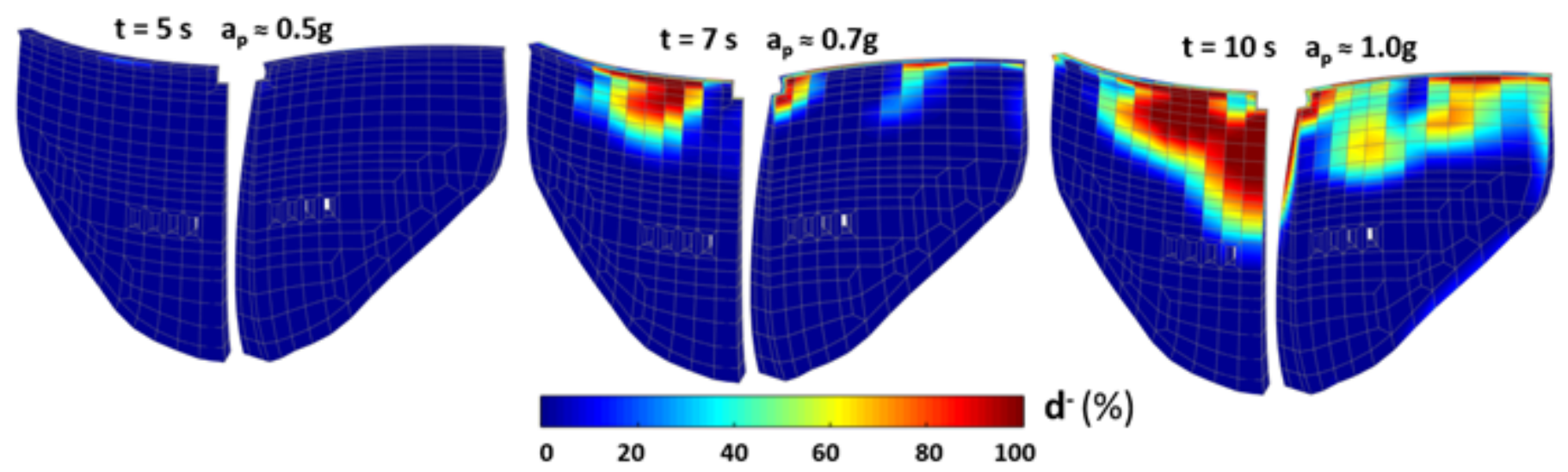
Figure 22

Non-linear seismic behavior of Cahora Bassa dam. Performance for increasing ETA excitation levels: evolution of tensile (a) and compressive damage distributions (b). 